Review

\title{
NiFe-based nanostructures on nickel foam as highly efficiently electrocatalysts for oxygen and hydrogen evolution reactions
}

\author{
Wei Zhang a,b,c, Daohao Li ${ }^{\mathrm{a}, \mathrm{b}, \mathrm{c}}$, Longzhou Zhang ${ }^{\mathrm{d}}$, Xilin She ${ }^{\mathrm{a}, \mathrm{b}, \mathrm{c}, *}$, Dongjiang Yang a,b,c,e,* \\ a State Key Laboratory of Biopolysaccharide Fibers and Ecological Textiles, China \\ ${ }^{\mathrm{b}}$ Co-Innovation Center of Marine Biomass Fibers and Textiles of Shandong Province, China \\ ${ }^{c}$ College of Materials Science and Engineering, Qingdao University, Qingdao 266071, Shandong, China \\ d School of Materials Science and Engineering, Yunnan Key Laboratory for Micro/Nano Materials \& Technology, Yunnan University, Kunming 650091, \\ Yunnan, China \\ e School of Natural Sciences and Queensland, Micro- and Nanotechnology Centre, Griffith University, Nathan Campus 4111, Australia
}

\section{A R T I C L E I N F O}

\section{Article history:}

Received 29 October 2018

Revised 21 January 2019

Accepted 25 January 2019

Available online $\mathrm{xxx}$

\section{Keywords:}

Electrocatalysis

NiFe compound

Nickel foam

HER

OER

\begin{abstract}
A B S T R A C T
Water splitting, as an advanced energy conversion technology, consists of two half reactions, including oxygen evolution reaction (OER) and hydrogen evolution reaction (HER). However, the ideal electrocatalysts are noble metal based catalysts. Their high cost and scarcity in earth seriously restrict the large deployments. NiFe-based materials have attracted great attention in recent years due to their excellent catalytic properties for OER and HER. Nevertheless, their conductivity and electrochemical stability at high current density are unsatisfactory, resulting in ineffective water splitting due to high impedance and low stability. Recently, a series of catalysts coating NiFe-based materials on 3D nickel foam were found to be extremely stable under the circumstance of high current density. In this review, we summarized the recent advances of NiFe-based materials on nickel foam for OER and HER, respectively, and further provided the perspectives for their future development.
\end{abstract}

(c) 2019 Published by Elsevier B.V. and Science Press on behalf of Science Press and Dalian Institute of Chemical Physics, Chinese Academy of Sciences

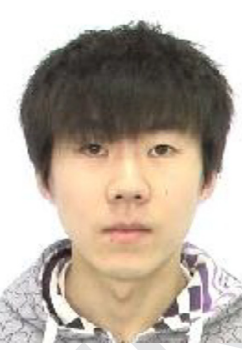

Wei Zhang is currently a master student in materials science at Qingdao University. His research interest focus on the study of electrocatalysis, especially for hydrogen evolution reaction (HER) and oxygen evolution reaction (OER).

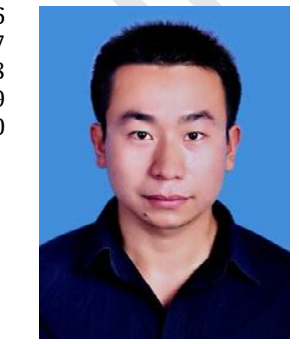

Daohao Li received his doctoral degree from Qingdao University in 2018. His current research mainly focuses on the design and development of functional nano-materials for energy storage applications, especially for supercapacitors and lithium/sodium ion batteries.

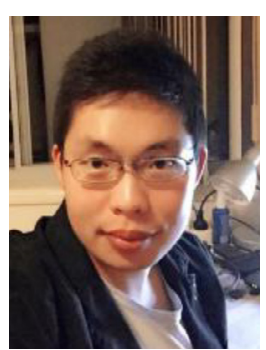

Longzhou Zhang got the B.E. degree from Xi'an Jiaotong University (China) in 2012 and then received his Ph.D. degree in inorganic chemistry from Griffith University (Australia) in 2018. In the November of 2018, he joined Yunnan University as a research fellow. His research focuses on the nanomaterials for electrocatalytic reactions, especially on the defective carbons and atomic metal catalysts.

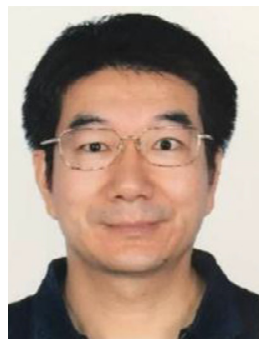

Prof. Xilin She received his M.S, degree from Qingdao University in 2002, and received his Ph.D. from Beijing University of Chemical Technology in 2005. His research interest include the fabrication of versatile functional nanomaterials and electrodes for energy storage and conversion devices.

* Corresponding authors at: College of Materials Science and Engineering, Qingdao University, Qingdao 266071, Shandong, China.

E-mail addresses: xlshe@qdu.edu.cn (X. She), d.yang@qdu.edu.cn (D. Yang). 

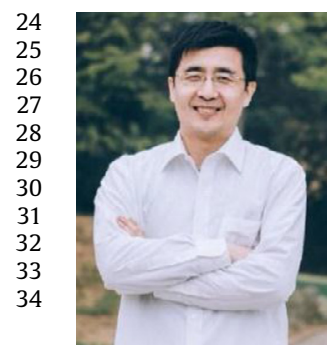

Prof. Dongiiang Yang received his Ph.D. in Physical Chemistry from Chinese Academy of Sciences in 2006. Then he went to the Queensland University of Technology and Griffith University to work as a postdoctoral fellow. $\mathrm{He}$ is now working as a research fellow at Queensland Micro- and Nanotechnology Centre (QMNC) of Griffith University (Australia). He joined Qingdao University as a professor in 2012. His research interests mainly focus on functional materials for energy storage \& conversion with fuel cells and batteries, such as zinc-air/lithium/sodiumion batteries.

\section{Introduction}

The accelerating depletion of fossil fuels and the ever-growing issue of environment have attracted widespread concerns. The development of new energy resource has become an urgent challenge [1-3]. In this regard, as a highly efficient and clean technology, electrochemical water splitting (WS) is easily coupled to other renewable energy resource, such as wind power, wave power and solar energy, and stands out in various hydrogen production technologies. It is well known that WS is composed of oxygen evolution reaction (OER) and hydrogen evolution reaction (HER) processes [4-6]. However, the practical applications of WS are restrained due to the high overpotentials of anodic OER and cathodic HER $[7,8]$. Thus, it is necessary to develop an efficient catalyst to reduce the overpotentials of WS. Currently, Ru/Ir- and Pt-based materials are the most efficient catalysts for OER and HER, respectively $[9,10]$. However, these high cost and scarce catalysts impede the widespread application of WS. Moreover, due to the inharmonious of optimum electrolyte $\mathrm{pH}$, most of catalysts become difficult to trigger WS efficiently when they are in an integrated electrolyze [11]. Besides, the stability of catalysts is another important factor for application. Therefore, it is an urgent demand to design a catalyst with high activity, low cost and long-term stability to replace noble metal-based catalysts.

Recently, transition metals (such as Mn [12-14], Ni [15-17], Co [18-20] and $\mathrm{Fe}[21,22])$ based catalysts have been widely investigated for WS. Moreover, the combination of the two metals will tend to bring higher electrochemical performance towards OER and HER [23-28]. Significantly, compared with other electrocatalysts (NiCo-based, NiMn-based, CoFe-based, etc.), NiFe-based catalysts show superior performance in both OER and HER. More interestingly, $\mathrm{Ni}$ and $\mathrm{Fe}$ are always found together in the earth and trace $\mathrm{Fe}$ in $\mathrm{Ni}(\mathrm{OH})_{2}$ electrodes can significantly improve OER performance of $\mathrm{Ni}(\mathrm{OH})_{2}$. According to the previous reports, $\mathrm{NiFeO}_{x} \mathrm{H}_{y}$ is regarded as the best OER catalyst. Besides, the excellent HER performance of NiFe-based catalysts has also been proved in many researches $[29,30]$. The reserves of $\mathrm{Ni}$ and $\mathrm{Fe}$ in earth are abundant, which can reduce the cost of commercialization. At present, there are two main methods for preparing WS catalyst electrodes [31]. The commonly used one is to drop a slurry composed of catalyst and conductive binder onto the electrodes [32-34]. However, such method has two drawbacks: (i) the electrical insulating binder used to make up slurry will decrease the contact area of catalyst and electrolytes, which will reduce the electrocatalytic performance [35]; (ii) the attached catalysts are liable to shed out from the electrode under high current density due to the large producing rate of $\mathrm{H}_{2} / \mathrm{O}_{2}$ bubbles, which causes a poor stability. In order to overcome the above bottlenecks, people combined the WS catalysts and conductive substrates as the another WS catalysts preparation method, such as carbon paper [36-41], copper foils [42-45], FTO [46-49], nickel foils [50-53], iron substrates [54], stainlesssteel [51,55] and nickel foam [56-58]. As a 3D porous substrate, nickel foam has the advantages of good electrical conductivity (accelerate the diffusion of electrons), high specific surface area (conductive to the dispersion of the catalysts) and the porous structure (diffuse the generated gas in timely) $[59,60]$. Therefore, the application of nickel foam in WS has attached great attention, especially at high current density. At present, more and more catalysts on nickel foam have been reported, which can withstand a long period of time at high current density. Thus, they attract much more attention for practical applications. Generally, the assembling of catalysts and nickel foam mainly includes hydrothermal reaction and electrodeposition. The hydrothermal reaction can obtain the catalysts with high purity, good crystallinity and regular morphology, but it is time consuming. The electrodeposition has the advantage of timesaving, but this approach has a complex operation with high cost in practical applications. We summarized the methods of NiFe-based electrocatalysts on nickel foam in Table 1.

There are several meaningful reviews about the NiFe-based electrocatalysts and the electrocatalysts on nickel foam [61]. However, no systematic review about the combination of them for OER and HER has been reported yet. Therefore, in this review, we summarize the reports of NiFe-based catalysts on nickel foam in OER and HER, respectively. This review will provide a more comprehensive understanding of NiFe-based electrocatalysts on nickel foam and provide some references for the design of such electrocatalysts in the future.

\section{Electrochemical parameters for oxygen and hydrogen evolution reactions}

Since the first report on WS with a cathode and an anode in an electrolyte in 1789, enormous efforts have been made to develop high-performance WS catalysts. Earlier comparisons of catalytic performance focused on the current density at a certain overpotential. With the deepening of research, there are several main parameters to evaluate the catalytic performance such as, overpotential (Fig. 1(a) and (b)), Tafel slope (Fig. 1(c)), electrochemical impedance spectrum (EIS) (Fig. 1(d)), electrochemical active surface area (ECSA) (Fig. 1(e) and (f)), turnover frequency (TOF) (Fig. 1(g)), faraday efficiency and stability (Fig. 1(h)) [5,10,62].

\subsection{Onset overpotential and overpotential}

The onset overpotential generally refers to the applied potential when the obvious current begins to appear. However, it is difficult to determine the precise potential values due to external factors such as materials and environment. To compare the activity of catalysts quantitatively, scientists make the overpotential at $10 \mathrm{~mA} \mathrm{~cm}^{-2}$ as an important Ref. [63]. In addition, for the performance of catalysts based on nickel foam, the overpotential at a higher current density is another evaluation parameter. In brief, an ideal catalytic material requires a higher current density at lower overpotential. In order to unify the standard of evaluation, the $\mathrm{Ag} / \mathrm{AgCl}$ electrode and the saturated calomel electrode (SCE) are used as a Ref. [64]. The final data should be converted to the potential vs. RHE according to the calculation below:

$$
\begin{array}{ll}
E_{R H E}=E_{A g / A g C l}+E_{A g / A g C l}^{0}+0.059 * p H & \left(E_{A g / A g C l}^{0}=0.197 \mathrm{~V}\right) \\
E_{R H E}=E_{S C E}+E_{S C E}^{0}+0.059 * p H & \left(E_{A g / A g C l}^{0}=0.242 \mathrm{~V}\right)
\end{array}
$$

\subsection{Tafel plot}

The Tafel slope, which can be obtained from three methods, acts as an important character in determining the reaction kinetics of OER and HER [65]. The first method is calculated from the LSV linear, according to the Tafel equation $(\eta=b \times \log j+a$, where $\eta$ is overpotential, $j$ is the current density, and $b$ is the Tafel slope). This is the most commonly used method because it is calculated under low overpotential and without bubbles interference. The second method is to directly obtain it by use of electrochemical workstation, in which the test voltage should be consistent with the 
Table 1. The comparison of the different methods to construct NiFe-based electrocatalysts on nickel foam.

\begin{tabular}{|c|c|c|c|c|}
\hline Catalyst/nickel foam & Method & Materials & Reaction condition & Ref. \\
\hline NiFe-LDH & Hydrothermal reaction & Nickel foam, $\mathrm{Ni}\left(\mathrm{NO}_{3}\right)_{2}, \mathrm{Fe}\left(\mathrm{NO}_{3}\right)_{3}$, urea & $120^{\circ} \mathrm{C}, 12 \mathrm{~h}$ & [88] \\
\hline $\mathrm{FeNi}_{10-x} \mathrm{Co}_{x}-\mathrm{LDH}$ & Hydrothermal reaction & $\begin{array}{l}\text { Nickel foam, } \mathrm{Fe}\left(\mathrm{NO}_{3}\right)_{3}, \mathrm{NiCl}_{2}, \mathrm{CoCl}_{2} \text {, urea, } \\
\text { trisodium citrate; }\end{array}$ & $150^{\circ} \mathrm{C}, 2$ day & [94] \\
\hline $\mathrm{Fe}-\mathrm{Ni}(\mathrm{OH})_{2}$ & Hydrothermal reaction & Nickel foam, $\mathrm{FeCl}_{3} ; \mathrm{HCl}$ & $180^{\circ} \mathrm{C}, 6 \mathrm{~h}$ & [64] \\
\hline NiFeRu-LDH & Hydrothermal reaction & Nickel foam, $\mathrm{Ni}\left(\mathrm{NO}_{3}\right)_{2}, \mathrm{Fe}\left(\mathrm{NO}_{3}\right)_{3}, \mathrm{RuCl}_{3}$, urea & $120^{\circ} \mathrm{C}, 12 \mathrm{~h}$ & [97] \\
\hline NiFeV-LDH & Hydrothermal reaction & Nickel foam, $\mathrm{Ni}\left(\mathrm{NO}_{3}\right)_{2}, \mathrm{Fe}\left(\mathrm{NO}_{3}\right)_{3}, \mathrm{VCl}_{3}$ & $120^{\circ} \mathrm{C}, 12 \mathrm{~h}$ & [98] \\
\hline NiFe-LDH & Electrodeposition & Nickel foam, $\mathrm{FeSO}_{4}, \mathrm{Ni}\left(\mathrm{NO}_{3}\right)_{2}$ & Room temperature, $<300 \mathrm{~s}$ & [93] \\
\hline $\mathrm{NiFeAl}_{x}-\mathrm{LDH}$ & Hydrothermal reaction & $\begin{array}{l}\text { Nickel foam, } \mathrm{Ni}\left(\mathrm{NO}_{3}\right)_{2}, \mathrm{Fe}\left(\mathrm{NO}_{3}\right)_{3}, \mathrm{Al}\left(\mathrm{NO}_{3}\right)_{3} \text {, } \\
\text { triethanolamine, hexamethylenetetramine }\end{array}$ & $95^{\circ} \mathrm{C}, 10 \mathrm{~h} ; 6 \mathrm{M} \mathrm{HCl}, 15 \mathrm{~min}$ & [95] \\
\hline NiFeMo & Hydrothermal reaction & $\begin{array}{l}\text { Nickel foam, } \mathrm{NiAc}_{2}, \mathrm{Fe}\left(\mathrm{NO}_{3}\right)_{3},\left(\mathrm{NH}_{4}\right)_{6} \mathrm{Mo}_{7} \mathrm{O}_{24} \text {, } \\
\text { urea }\end{array}$ & $160{ }^{\circ} \mathrm{C}, 2-10 \mathrm{~h}$ & {$[102]$} \\
\hline $\mathrm{FeNi}_{3} \mathrm{~N}$ & Oil bath and $\mathrm{NH}_{3}$ atmosphere & Nickel foam, $\mathrm{FeCl}_{2}$, trisodium citrate; $\mathrm{NH}_{3}$ & Oil bath: $90{ }^{\circ} \mathrm{C}, 6 \mathrm{~h} ; \mathrm{NH}_{3}: 500^{\circ} \mathrm{C}, 2 \mathrm{~h}$ & [109] \\
\hline $\mathrm{N}-(\mathrm{Ni}, \mathrm{Fe})_{3} \mathrm{~S}_{2}$ & Solid reaction & Nickel foam, thiourea & $500{ }^{\circ} \mathrm{C}, 2 \mathrm{~h}$ & [113] \\
\hline $\mathrm{Fe}_{2} \mathrm{Ni}_{2} \mathrm{~N}$ & $\begin{array}{l}\text { Hydrothermal reaction and } \\
\mathrm{NH}_{3} \text { atmosphere }\end{array}$ & Nickel foam, $\mathrm{Ni}\left(\mathrm{NO}_{3}\right)_{2}, \mathrm{Fe}\left(\mathrm{NO}_{3}\right)_{3}$, urea; $\mathrm{NH}_{3}$ & $\begin{array}{l}\text { Hydrothermal reaction: } 120^{\circ} \mathrm{C}, 12 \mathrm{~h} ; \mathrm{NH}_{3}: \\
380^{\circ} \mathrm{C}, 2 \mathrm{~h}\end{array}$ & [114] \\
\hline$\left(\mathrm{Ni}_{0.33} \mathrm{Fe}_{0.67}\right)_{2} \mathrm{P}$ & $\begin{array}{l}\text { Hydrothermal reaction and } \\
\text { solid reaction }\end{array}$ & $\begin{array}{l}\text { Nickel foam, } \mathrm{Ni}\left(\mathrm{NO}_{3}\right)_{2}, \mathrm{Fe}\left(\mathrm{NO}_{3}\right)_{3} \text {, urea; } \\
\mathrm{NaH}_{2} \mathrm{PO}_{2}\end{array}$ & $\begin{array}{l}\text { Hydrothermal reaction: } 120^{\circ} \mathrm{C}, 12 \mathrm{~h} \text {; solid } \\
\text { reaction: } 300^{\circ} \mathrm{C}, 2 \mathrm{~h}\end{array}$ & [120] \\
\hline $\mathrm{Ni}_{1.85} \mathrm{Fe}_{0.15} \mathrm{P}$ & $\begin{array}{l}\text { Hydrothermal reaction and } \\
\text { solid reaction }\end{array}$ & $\begin{array}{l}\text { Nickel foam, } \mathrm{Ni}\left(\mathrm{NO}_{3}\right)_{2}, \mathrm{Fe}\left(\mathrm{NO}_{3}\right)_{3} \text {, } \\
\text { hexamethylene tetramine; } \mathrm{NaH}_{2} \mathrm{PO}_{2}\end{array}$ & $\begin{array}{l}\text { Hydrothermal reaction: } 100^{\circ} \mathrm{C}, 10 \mathrm{~h} \text {; solid } \\
\text { reaction: } 300^{\circ} \mathrm{C}, 2 \mathrm{~h}\end{array}$ & [121] \\
\hline NiFe-OH/NiFeP & $\begin{array}{l}\mathrm{PH}_{3} \text { gas plasma-assisted } \\
\text { approach and Electrodeposition }\end{array}$ & Nickel foam, $\mathrm{PH}_{3}, \mathrm{Ni}\left(\mathrm{NO}_{3}\right)_{2}, \mathrm{Fe}\left(\mathrm{NO}_{3}\right)_{3}$ & $\begin{array}{l}\mathrm{PH}_{3} \text { gas plasma-assisted approach: } 200{ }^{\circ} \mathrm{C} \text {, } \\
15 \mathrm{~min} \text {; electrodeposition: } 15 \mathrm{~min},-1 \mathrm{~V} \text { vs. } \\
\mathrm{Ag} / \mathrm{AgCl}\end{array}$ & [122] \\
\hline$\left(\mathrm{Ni}_{0.5} \mathrm{Fe}_{0.5}\right)_{2} \mathrm{P}$ & $\begin{array}{l}\text { Hydrothermal reaction and } \\
\text { solid reaction }\end{array}$ & $\begin{array}{l}\text { Nickel foam, } \mathrm{Ni}\left(\mathrm{NO}_{3}\right)_{2}, \mathrm{FeSO}_{4} \text {, urea, } \mathrm{NH}_{4} \mathrm{~F} \text {; } \\
\mathrm{NaH}_{2} \mathrm{PO}_{2}\end{array}$ & $\begin{array}{l}\text { Hydrothermal reaction: } 100{ }^{\circ} \mathrm{C}, 8 \mathrm{~h} \text {; solid } \\
\text { reaction: } 400^{\circ} \mathrm{C}, 2 \mathrm{~h}\end{array}$ & [123] \\
\hline $\mathrm{Fe}_{11.8 \%}-\mathrm{Ni}_{3} \mathrm{~S}_{2}$ & Hydrothermal reaction & Nickel foam, $\mathrm{FeSO}_{4}$, L-cysteine & $150{ }^{\circ} \mathrm{C}, 10 \mathrm{~h}$ & [125] \\
\hline $\mathrm{Ni}_{0.7} \mathrm{Fe}_{0.3} \mathrm{~S}_{2}$ & $\begin{array}{l}\text { Hydrothermal reaction and } \\
\text { solid reaction }\end{array}$ & Nickel foam, $\mathrm{Ni}\left(\mathrm{NO}_{3}\right)_{2}, \mathrm{FeSO}_{4}$, urea, $\mathrm{NH}_{4} \mathrm{~F} ; \mathrm{S}$ & $\begin{array}{l}\text { Hydrothermal reaction: } 100^{\circ} \mathrm{C}, 8 \mathrm{~h} \text {; solid } \\
\text { reaction: } 300^{\circ} \mathrm{C}, 1 \mathrm{~h}\end{array}$ & [126] \\
\hline $\mathrm{Ni}_{2} \mathrm{FeS}_{4}$ & Electrodeposition & Nickel foam, $\mathrm{NiCl}_{2}$, thiourea & $\begin{array}{l}-1.2 \mathrm{~V} \text { and }+0.2 \mathrm{~V}(\mathrm{vs} . \mathrm{Ag} / \mathrm{AgCl} \text { ) at a scan rate of } \\
5 \mathrm{mV} \mathrm{s}^{-1}, 15 \text { sweep cycles }\end{array}$ & [127] \\
\hline $\mathrm{NiFeP}$ & Solid reaction & Nickel-iron foam, Red P. & $450^{\circ} \mathrm{C}, 3 \mathrm{~h}$ & [139] \\
\hline NiFe-P & Electrodeposition & Nickel foam, $\mathrm{NiSO}_{4}, \mathrm{FeSO}_{4}, \mathrm{NaH}_{2} \mathrm{PO}_{2}, \mathrm{NaOAc}$ & $\begin{array}{l}-1 \mathrm{~V} \text { and }-0.3 \mathrm{~V} \\
\left(\mathrm{vs} . \mathrm{Ag} / \mathrm{AgCl} \text { ) at a scan rate of } 5 \mathrm{mV} \mathrm{s}^{-1} \text { for } 15\right. \\
\text { sweep cycles }\end{array}$ & [142] \\
\hline $\mathrm{FeNiP}_{x}$ & Water bath and solid reaction & Nickel foam, $\mathrm{FeCl}_{2}$, trisodium citrate, $\mathrm{NaH}_{2} \mathrm{PO}_{2}$ & Water bath: $90^{\circ} \mathrm{C}, 6 \mathrm{~h}$; solid reaction: $300^{\circ} \mathrm{C}, 2 \mathrm{~h}$ & [143] \\
\hline $\mathrm{Fe}-\mathrm{Ni}_{3} \mathrm{~S}_{2}$ & $\begin{array}{l}\text { Hydrothermal reaction and ion } \\
\text { exchange reaction }\end{array}$ & $\begin{array}{l}\text { Nickel foam, } \mathrm{Ni}\left(\mathrm{NO}_{3}\right)_{2}, \mathrm{Fe}\left(\mathrm{NO}_{3}\right)_{3} \text {, urea, } \mathrm{NH}_{4} \mathrm{~F} \text {; } \\
\mathrm{Na}_{2} \mathrm{~S}\end{array}$ & $\begin{array}{l}\text { Hydrothermal reaction: } 120^{\circ} \mathrm{C}, 6 \mathrm{~h} \text {; ion } \\
\text { exchange reaction: } 100^{\circ} \mathrm{C}, 8 \mathrm{~h}\end{array}$ & [150] \\
\hline FeNi-S film & Electrodeposition & Nickel foam, $\mathrm{Ni}\left(\mathrm{NO}_{3}\right)_{2}, \mathrm{Fe}\left(\mathrm{NO}_{3}\right)_{3}$, thiourea & $\begin{array}{l}50{ }^{\circ} \mathrm{C},-1.2 \mathrm{~V} \text { and } 0.2 \mathrm{~V} \text { (vs. } \mathrm{Ag} / \mathrm{AgCl} \text { ) at a scan } \\
\text { rate of } 20 \mathrm{mV} \mathrm{s}^{-1} \text { for } 20 \text { sweep cycles }\end{array}$ & [152] \\
\hline$\left(\mathrm{Fe}_{0.048} \mathrm{Ni}_{0.952}\right)_{2} \mathrm{P}$ & $\begin{array}{l}\text { Hydrothermal reaction and } \\
\text { solid reaction }\end{array}$ & $\begin{array}{l}\text { Nickel foam, } \mathrm{Ni}\left(\mathrm{NO}_{3}\right)_{2}, \mathrm{Fe}\left(\mathrm{NO}_{3}\right)_{3} \text {, urea, } \mathrm{NH}_{4} \mathrm{~F} \text {; } \\
\mathrm{NaH}_{2} \mathrm{PO}_{2}\end{array}$ & $\begin{array}{l}\text { Hydrothermal reaction: } 140^{\circ} \mathrm{C}, 12 \mathrm{~h} \text {; solid } \\
\text { reaction: } 450^{\circ} \mathrm{C}, 3 \mathrm{~h}\end{array}$ & [69] \\
\hline
\end{tabular}

voltage range of the LSV test. The third one is to calculate the Tafel slopes from the plot of $\log R_{\mathrm{ct}} \mathrm{vs}$. overpotential, in which $R_{\mathrm{ct}}$ represents the charge transfer resistance in the equivalent circuit fitted in impedance spectroscopy. Tafel slopes obtained from this method reflect purely the charge transfer kinetics, compared with Tafel slopes obtained from the above two methods which may include contributions from catalyst resistance. The obtained Tafel slopes can provide significant kinetic information on the reaction mechanism. For example, the lower Tafel value represents the faster reaction kinetics. The exchange current density $\left(j_{0}\right)$ is another important parameter that can reflect the intrinsic electrocatalytic activity. It can be obtained from the Tafel equation $(\eta=b \times \log$ $j+a$ ) when $\eta$ is assumed to be zero. The calculated $j_{0}$ is considered to be proportional to the catalytic active surface area. The large $j_{0}$ indicates the large surface area and fast electron transfer rate. Therefore, the high-performance electrocatalysts in OER and HER should have low Tafel slope and high exchange current density [66].

\subsection{Electrochemical impedance spectrum (EIS)}

EIS is a small amplitude alternating current (AC) signal with different frequencies, which is to measure the ratio of $A C$ signal voltage to current (that ratio is the impedance of the system) with the variation of sinusoidal frequency $(\omega)$ or the phase angle $(\Phi)$ of impedance varies with $\omega$. It can probe the kinetics of WS and the electrode/electrolyte interface reactions. The semicircle in the Nyquist plot attributes to the charge-transfer resistance $\left(R_{\mathrm{ct}}\right)$, which is related to the interface charge-transfer process of the electrode. The smaller diameter of the semicircles means the lower $R_{\mathrm{ct}}$ and the lower $R_{\mathrm{ct}}$ value indicates a faster reaction rate [67].

\subsection{Electrochemical active surface area (ECSA)}

To understand the reaction mechanism of catalysts, the ECSA of the catalysts are investigated based on the electrochemical double-layer capacitance $\left(C_{\mathrm{dl}}\right)$. The $C_{\mathrm{dl}}$ can be calculated from $\mathrm{CV}$ curves, which is tested in a certain potential window without the faradaic processes. In general, 5-10 consecutive CV curves at different sweep speeds $\left(5-200 \mathrm{mV} \mathrm{s}^{-1}\right)$ are taken. The obtained $\mathrm{CV}$ curves are preferably close to the rectangle. After selecting the intermediate value of the applied potential range, the difference of current density under the current potential is calculated $\left(\Delta j=j_{1}-j_{2}\right)$, and the slope is obtained by linear fitting with different sweep speeds as $X$-axis and $\Delta j$ as $Y$-axis. The slope is twice the value of $C_{\mathrm{dl}}$. The larger value represents higher current density and more exposed surface reactive sites [68].

\subsection{Turnover frequency (TOF)}

At present, in the process of electrochemical measurement, especially for the electrocatalysts grown on the substrate, it is not easy to exactly determine the loading amount of a catalyst. In order to solve this problem, TOF has been proposed to characterize 
(a)

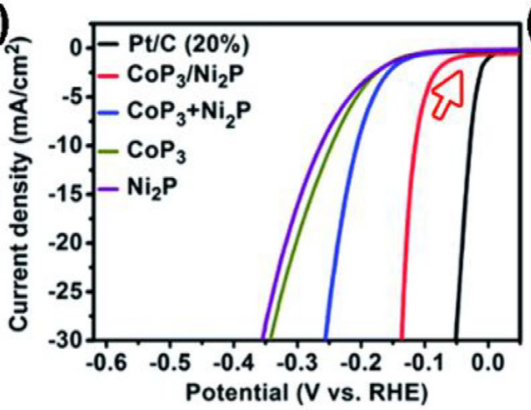

(d)

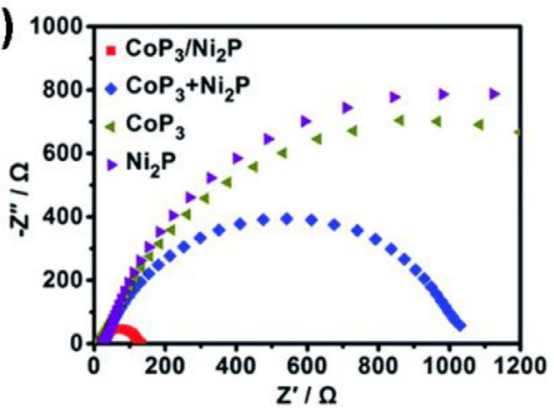

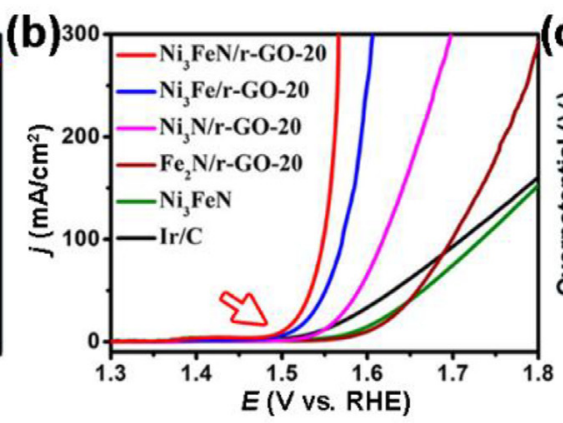
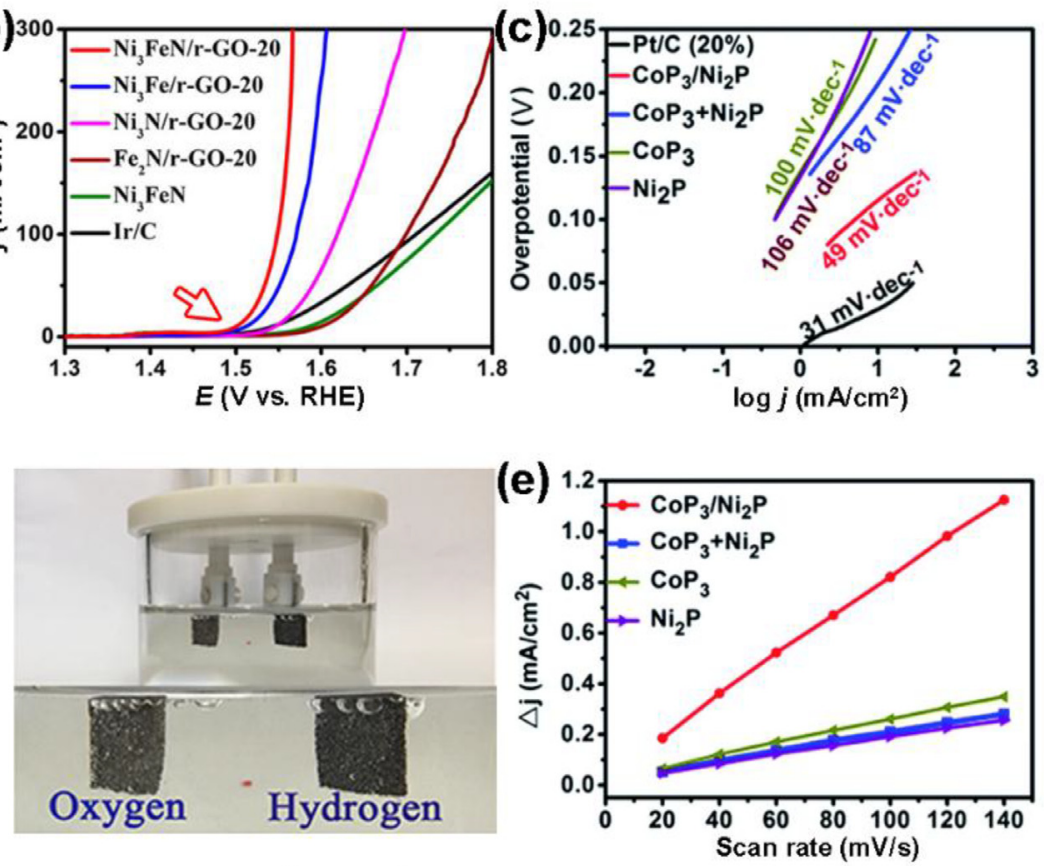

(f)
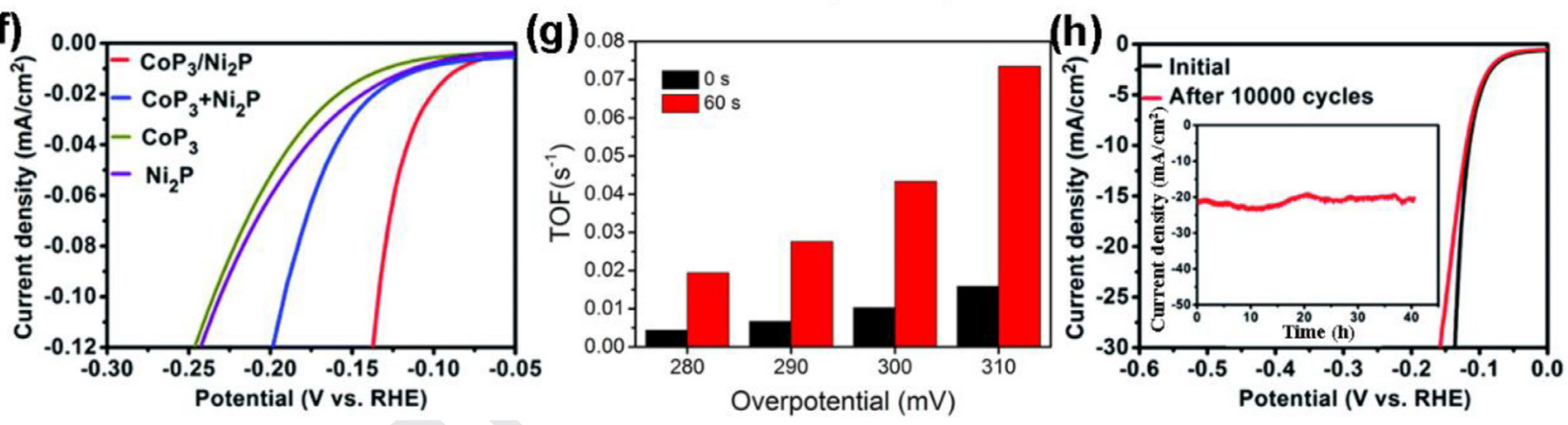

Fig. 1. The parameters of evaluating the catalytic performance. (a) and (b) LSV of HER and OER; (c) Tafel slope; (d) EIS; (e) $C_{\mathrm{dl}}$; (f) ECSA; (g) TOF; (h) Stability [62].

the performance of catalysts widely. The value of TOF is defined as the amount of reactants that per unit of catalytic active site in unit time can be converted into a desired product. The TOF $\left(\mathrm{s}^{-1}\right)$ can be calculated according to the following equation:

$\mathrm{TOF}=\frac{J \times A}{(\alpha \times F \times n)}$

Where $J\left(\mathrm{~mA} \mathrm{~cm}^{-2}\right)$ is the current density at a given overpotential during the LSV measurement; $A$ is the area of the working electrode; $\alpha$ is the electron number of the target product; $F$ is the Faraday constant (a value of $96485.3 \mathrm{C} \mathrm{mol}^{-1}$ ); $n$ (mol) is the number of moles of the active materials. The TOF value is useful for comparing the property of similar catalysts and the high TOF value represents higher catalytic activity [62].

\subsection{Faraday efficiency (FE)}

FE is a term commonly used in electrochemical fields such as fuel cells and water electrolysis reaction, which can be understood as the percentage of actual products and theoretical products. For the WS, the FE is equal to the ratio of the amount of gas produced by experiment to the amount of gas produced theoretically, and plays an important role in analyzing the reaction process of the catalysts [11].

\subsection{Stability}

In addition to excellent electrochemical performance, long-term stability of an electrocatalyst is important, as it directly determines whether the materials can be developed for practical applications. Generally, two main methods are often used: cyclic CV method and chronoamperometry ( $E-t$ curve) or chronopotentiometry test (I-t curve). E- $t$ curve or chronopotentiometry is measured for a long period with a given applied potential or current density. The given applied potential and current density should generally ensure that the current density is larger than $10 \mathrm{~mA} \mathrm{~cm}{ }^{-2}$. Normally, more than $20 \mathrm{~h}$ of testing can be used as a benchmark for an ideal catalyst [69].

\section{NiFe-based electrocatalysts on nickel foam for OER}

Since the OER undergoes four electrons pathway, the OER requires more energy input than HER (two electrons pathway) [70]. Thus, most of the OER catalysts tend to exhibit higher overpotentials, and the OER plays an essential role in WS [44,71]. The sluggish OER can significantly hinder the efficiency of the overall reactions and thus impede the practical application. Therefore, developing stable and efficient OER catalysts with low overpotential is still profoundly desired. 
Table 2. The performance of the NiFe-based electrocatalysts in OER.

\begin{tabular}{|c|c|c|c|c|c|}
\hline Catalyst/nickel foam & Electrolyte & $\eta$ at $\mathrm{x} \mathrm{mA} \mathrm{cm}-2(\mathrm{mV})$ & Tafel slope (mV dec $\left.{ }^{-1}\right)$ & Stability & Ref. \\
\hline NiFe-LDH & $0.1 \mathrm{KOH}$ & $\eta_{30}=280$ & 50 & More than $10 \mathrm{~h}$ at $200 \mathrm{~mA} \mathrm{~cm}^{-2}(1.0 \mathrm{KOH})$ & [88] \\
\hline $\mathrm{FeNi}_{10-x} \mathrm{Co}_{x}-\mathrm{LDH}$ & $1.0 \mathrm{KOH}$ & $\eta_{10}=220$ & 42 & More than $11 \mathrm{~h}$ at $10 \mathrm{~mA} \mathrm{~cm}-2(1.0 \mathrm{KOH})$ & [94] \\
\hline $\mathrm{Fe}-\mathrm{Ni}(\mathrm{OH})_{2}$ & $1.0 \mathrm{KOH}$ & $\eta_{10}=260$ & 51.5 & More than $100 \mathrm{~h}$ & [64] \\
\hline NiFeRu-LDH & $1.0 \mathrm{KOH}$ & $\eta_{10}=225$ & 31 & More than $10 \mathrm{~h}$ at $10 \mathrm{~mA} \mathrm{~cm}-2(1.0 \mathrm{KOH})$ & [97] \\
\hline NiFeV-LDH & $1.0 \mathrm{KOH}$ & $\eta_{20}=260$ & 42 & More than $18 \mathrm{~h}$ at $\sim 190 \mathrm{~mA} \mathrm{~cm}^{-2}(1.0 \mathrm{KOH})$ & [98] \\
\hline NiFe-LDH & $1.0 \mathrm{KOH}$ & $\eta_{10}=224$ & 52.8 & More than $50 \mathrm{~h}$ & [93] \\
\hline $\mathrm{NiFeAl}_{x}-\mathrm{LDH}$ & $1.0 \mathrm{KOH}$ & $\eta_{20}=304$ & 50 & More than $18 \mathrm{~h}$ at $20 \mathrm{~mA} \mathrm{~cm}-2(1.0 \mathrm{KOH})$ & [95] \\
\hline NiFeMo & $1.0 \mathrm{KOH}$ & $\eta_{10}=280$ & 40 & More than $24 \mathrm{~h}$ & [102] \\
\hline $\mathrm{FeNi}_{3} \mathrm{~N}$ & $1.0 \mathrm{KOH}$ & $\eta_{10}=202$ & 98 & More than $60 \mathrm{~h}$ at $100 \mathrm{~mA} \mathrm{~cm}-2(1.0 \mathrm{KOH})$ & [109] \\
\hline $\mathrm{N}-(\mathrm{Ni}, \mathrm{Fe})_{3} \mathrm{~S}_{2}$ & $1.0 \mathrm{KOH}$ & $\eta_{170}=350$ & 70 & More than $10000 \mathrm{~s}$ at $\sim 50 \mathrm{~mA} \mathrm{~cm}{ }^{-2}(1.0 \mathrm{KOH})$ & [113] \\
\hline $\mathrm{Fe}_{2} \mathrm{Ni}_{2} \mathrm{~N}$ & $1.0 \mathrm{KOH}$ & $\eta_{100}=250$ & 34 & More than $10 \mathrm{~h}$ at $\sim 150 \mathrm{~mA} \mathrm{~cm}^{-2}(1.0 \mathrm{KOH})$ & {$[114]$} \\
\hline$\left(\mathrm{Ni}_{0.33} \mathrm{Fe}_{0.67}\right)_{2} \mathrm{P}$ & $1.0 \mathrm{KOH}$ & $\eta_{50}=230 \mathrm{mV}$ & 55.9 & More than $24 \mathrm{~h}$ at $\sim 170 \mathrm{~mA} \mathrm{~cm}^{-2}(1.0 \mathrm{KOH})$ & [120] \\
\hline $\mathrm{Ni}_{1.85} \mathrm{Fe}_{0.15} \mathrm{P}$ & $1.0 \mathrm{KOH}$ & $\eta_{20}=270 \mathrm{mV}$ & 96 & More than $10 \mathrm{~h}$ at $100 \mathrm{~mA} \mathrm{~cm}-2(1.0 \mathrm{KOH})$ & [121] \\
\hline $\mathrm{NiFe}-\mathrm{OH} / \mathrm{NiFeP}$ & $1.0 \mathrm{KOH}$ & $\eta_{10}=199 \mathrm{mV}$ & 39 & More than $24 \mathrm{~h}$ at $10 \mathrm{~mA} \mathrm{~cm}-2(1.0 \mathrm{KOH})$ & {$[122]$} \\
\hline$\left(\mathrm{Ni}_{0.5} \mathrm{Fe}_{0.5}\right)_{2} \mathrm{P}$ & $1.0 \mathrm{KOH}$ & $\eta_{20}=219 \mathrm{mV}$ & 57 & More than $24 \mathrm{~h}$ at $20 \mathrm{~mA} \mathrm{~cm}^{-2}(1.0 \mathrm{KOH})$ & [123] \\
\hline $\mathrm{Fe}_{11.8 \%}-\mathrm{Ni}_{3} \mathrm{~S}_{2}$ & $1.0 \mathrm{KOH}$ & $\eta_{100}=253 \mathrm{mV}$ & 65.5 & More than $14 \mathrm{~h}$ & [125] \\
\hline $\mathrm{Ni}_{0.7} \mathrm{Fe}_{0.3} \mathrm{~S}_{2}$ & $1.0 \mathrm{KOH}$ & $\eta_{10}=198 \mathrm{mV}$ & 56 & More than $5000 \mathrm{~s}$ at $10 \mathrm{~mA} \mathrm{~cm}-2(1.0 \mathrm{KOH})$ & [126] \\
\hline $\mathrm{Ni}_{2} \mathrm{FeS}_{4}$ & $1.0 \mathrm{KOH}$ & $\eta_{100}=231 \mathrm{mV}$ & 55 & More than $200 \mathrm{~h}$ at $80 \mathrm{~mA} \mathrm{~cm}-2(1.0 \mathrm{KOH})$ & {$[127]$} \\
\hline
\end{tabular}

At the early stage, most of the studies focused on precious metal catalysts. Among them, Ru-based and Ir-based materials were considered to be the highly efficient OER catalysts [72-75]. Nevertheless, their scarcity and high cost hinder the large-scale deployment. Recently, transition metal compounds came into view with the advantage of low cost and high activity for OER including $\mathrm{MnO}[76,77], \mathrm{FeO}[78,79], \mathrm{CoO}[80,81]$ and $\mathrm{NiO}[82,83]$. Some of them were coated on nickel foam to enhance the OER performance and high stability $[60,84,85]$. Particularly, the NiFe-based materials on nickel foam exhibit superior performance (Table 2).

\subsection{NiFe-LDH-based electrocatalysts on nickel foam for OER}

Due to the typical layered structure, the properties of NiFeLDHs can be adjusted in a wide range by tuning the ratio of $\mathrm{Ni}$ and $\mathrm{Fe}$, and the type of anions at the interlayers and the porosity [66,86-88]. This makes that NiFe-LDHs become a class of materials with great potential for energy conversion and storage. However, the original NiFe-LDH has poor electrical conductivity [88-90], which could result in the unsatisfactory performance. To solve this problem, some researchers assembled NiFe-LDH with the conductive nickel foam substrate [7]. In 2014, Lu et al. directly grow NiFe-LDH on nickel foam by using hydrothermal method [88]. The obtained NiFe-LDH film presents mesoporous structures with the thickness of $\sim 200-300 \mathrm{~nm}$ and the excellent OER performance in $1.0 \mathrm{M} \mathrm{KOH}$ (Fig. 2(a)-(c)). For instance, the onset overpotential of NiFe-LDH film $(\sim 230 \mathrm{mV})$ is smaller than those of $\beta-\mathrm{Ni}(\mathrm{OH})_{2}$ film $(\sim 450 \mathrm{mV})$ and nickel foam $(\sim 520 \mathrm{mV})$. After the OER test, the authors found that the NiFe-LDH is converted to $\mathrm{NiOOH}$ according to the Raman spectra results, which means that the real OER catalyst might be the $\mathrm{NiOOH}$. The structure reconstruction of NiFeLDH from hydroxide to oxyhydroxide during the OER process is also found by other groups [91,92], and the resultant oxyhydroxide phase might be the crucial factor of the outstanding OER activity towards NiFe-LDH. Also in 2014, Luo and co-workers combined the perovskite tandem cell with $\mathrm{NiFe-LDH}$ on nickel foam electrodes for water splitting [1]. Benefiting from the outstanding OER performance of NiFe-LDH on nickel foam, the efficiency of solar to hydrogen reaches as high as $12.3 \%$. Such combination provided a new form of energy conversion from solar energy to hydrogen production. In 2015, Duan's group reported a universal electrochemical approach to fabricate various LDH [93]. The approach has the advantage of saving time and cost, which provides a viable commercial route. The obtained NiFe-LDH on nickel foam from this method shows excellent OER performance $\left(\eta_{10}=224 \mathrm{mV}\right)$ and sta- bility of large current (50-250 $\mathrm{mA} \mathrm{cm}^{-2}$ ) for long time (more than $50 \mathrm{~h}$ ). After the stability test, the current density has no attenuation, which proved that the catalysts would have great potential in practical application of WS.

Recently, many efforts have been made to improve the activity of NiFe-LDH on nickel foam by heteroatom doping or defect making. Both of the onset overpotential and current density can be significantly improved by using the two methods [94,95]. Firstly, heteroatom doping could modify the electronic structure and improve the conductivity of the electrocatalyst, thus enhancing the OER performance [96]. Long et al. successfully introduced Co into NiFe-LDH and improved the catalytic performance of NiFe-LDH efficiently [94]. The authors synthesized ultra-thin FeNiCo-LDH by replacing Fe salt with Co salt. The atomic force microscopy (AFM) shows the thickness of LDHs decreased with the increase of Co doping amount. The thicknesses of $\mathrm{FeNi}_{9} \mathrm{Co}-\mathrm{LDH}$ and $\mathrm{FeNi}_{8} \mathrm{CO}_{2}-$ $\mathrm{LDH}$ are around $1.5-1.8 \mathrm{~nm}$ and $1.2-1.5 \mathrm{~nm}$, respectively. The LSV results show that the thinner $\mathrm{NiFe}_{8} \mathrm{Co}_{2}-\mathrm{LDH}$ with higher cobalt content shows the lower onset potential of $\sim 0.21 \mathrm{~V}$. They thought that the OER performance enhancement stems from Co substitution. With the development of the DFT calculation in WS, some works about heteroatom doping have been reemphasized. Chen and co-workers used the similar synthesized method to replace part of $\mathrm{Fe}\left(\mathrm{NO}_{3}\right)_{3}$ with $\mathrm{RuCl}_{3}$ in reactant to grow NiFeRu-LDH on nickel foam [97]. The NiFeRu-LDH shows a zero onset HER overpotential, and the current densities under the same overpotentials are larger than that of Pt/C. Through the DFT calculation, the water dissociation energy of NiFeRu-LDH is only $0.5 \mathrm{eV}$, much lower than that of NiFe-LDH $(1.02 \mathrm{eV})$. Li and co-workers reported the formation of the NiFeV-LDH on nickel foam through the common hydrothermal reaction with better OER performance than NiFe-LDH [98]. To achieve the current density of $20 \mathrm{~mA} \mathrm{~cm} \mathrm{~cm}^{-2}$, NiFeV-LDH only needs a low overpotential of $195 \mathrm{mV}$ compared that of NiFeLDH $(249 \mathrm{mV})$. Because the doped $\mathrm{V}$ can change the chemical environmental of Fe. the authors selected the Fe as the active sites, and calculated the Gibbs free energy. The calculated energy of rate determining step on NiFeV-LDH $(1.64 \mathrm{eV})$ is smaller than that on NiFe-LDH $(1.89 \mathrm{eV})$, which indicates that the doped $\mathrm{V}$ could decrease the OER energy barrier and thus enhances the OER performance of $\mathrm{NiFe}-\mathrm{LDH}$. Benefiting from the 3D porous structure, NiFeV-LDH supported on nickel foam shows the outstanding stability of more than $18 \mathrm{~h}$ at a high current density of $187 \mathrm{~mA} \mathrm{~cm}^{-2}$. Although this is still far from the current density required for commercial industrial electrolytic water $\left(1 \mathrm{~A} \mathrm{~cm}^{-2}\right)$, it has an enormous advantage over most reports $\left(10 \mathrm{~mA} \mathrm{~cm}^{-2}\right)$ [99]. The 

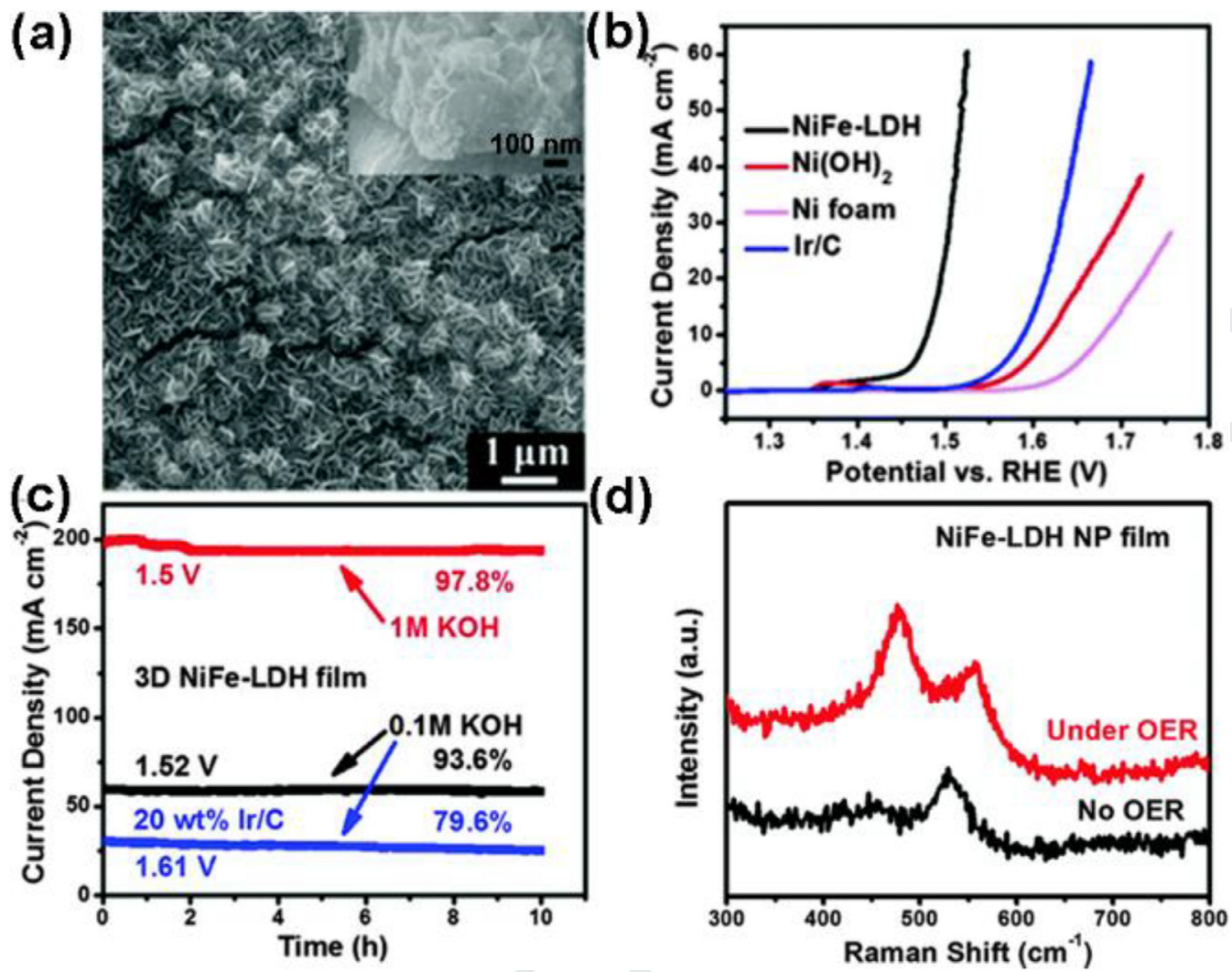

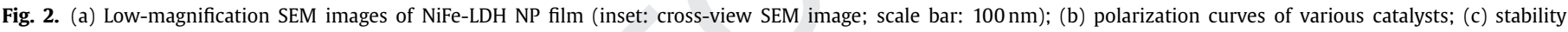

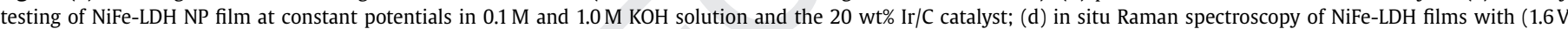
vs. RHE) and without OER operation [88].

changes in the chemical environment of metal sites after heteroatom doping are also discovered on $\mathrm{NiFeCr}$ on carbon paper reported by Yang and co-workers [100]. Such phenomenon is very important to study the mechanism of heteroatom doping in NiFeLDH. In addition, the catalytic performance of NiFe-LDH could be further enhanced by etching the substituted atoms and inducing defects. For example, as the $\mathrm{Al}^{3+}$ can partially dissolve in strong alkaline solution, the defective $\mathrm{NiFeAl}_{x}-\mathrm{LDH}$ was synthesized by Liu and co-workers [95]. The obtained $\mathrm{Ni}_{3} \mathrm{FeAl}_{0.91}$-LDH shows the best catalytic performance among the $\mathrm{Ni}_{3} \mathrm{FeAl}_{1.27}-\mathrm{LDH}, \mathrm{Ni}_{3} \mathrm{FeAl}_{2.73^{-}}$ $\mathrm{LDH}$ and nickel foam. The current density of $\mathrm{Ni}_{3} \mathrm{FeAl}_{0.91}-\mathrm{LDH}$ at the potential of $1.60 \mathrm{~V}$ vs. RHE is as high as $235 \mathrm{~mA} \mathrm{~cm}{ }^{-2}$, which is much higher than those of $\mathrm{Ni}_{3} \mathrm{Fe}-\mathrm{LDH}\left(53 \mathrm{~mA} \mathrm{~cm}{ }^{-2}\right), \mathrm{Ni}_{3} \mathrm{FeAl}_{1.27}$ LDH $\left(120 \mathrm{~mA} \mathrm{~cm}^{-2}\right), \mathrm{Ni}_{3} \mathrm{FeAl}_{2.73}-\mathrm{LDH}\left(105 \mathrm{~mA} \mathrm{~cm}{ }^{-2}\right)$ and pristine $\mathrm{Ni}$ foam $\left(20 \mathrm{~mA} \mathrm{~cm}^{-2}\right)$.

In addition to doping cations to improve the catalytic performance of OER, adjusting the anions between NiFe-LDH layers could significantly improve the performance of OER [101]. In 2105, Li's group directly fabricated NiFeMo-LDH onto nickel foam by hydrothermal method in the presence of urea as precipitant in [102]. The doped Mo atoms could form molybdate salt between the LDH layers with the assistance of urea (Fig. 3(a) and (b)). The formed $\mathrm{MoO}_{4}{ }^{2-}$ reduces the average thickness of LDHs to $0.5 \mathrm{~nm}$, which is much thinner than those of NiFe-LDHs prepared by other co-precipitation methods $[90,103,104]$. Such results indicate that the interlayer anions are critical to the formation of these ultra-thin LDHs. Although NiFeMo-LDH and NiFe-LDH have the same Tafel slope $\left(40 \mathrm{mV} \mathrm{dec}{ }^{-1}\right)$, the current density of NiFeMoLDH is obviously greater than that of $\mathrm{NiFe}-\mathrm{LDH}$ at the same overpotential.

Unfortunately, the real OER active site of NiFe-LDH is still undefined. Presently, there are two hypotheses about the real active sites of NiFe-LDH: the Ni active sites and Fe active sites. In early 356 research, people mainly thought that the OER activity of $\mathrm{Ni}$ is 357 higher than that of $\mathrm{Fe}$ in NiFe-LDH [105]. However, Friebel and 358 co-workers confirmed the high OER activity of $\mathrm{Fe}$ in $\mathrm{Ni}_{x} \mathrm{Fe}_{y} \mathrm{OOH} 359$ through density-functional theory (DFT) calculation. The authors 360 also debated that the Fe might act as the OER-active site when it incorporated into $\mathrm{NiOOH} \mathrm{[106].} \mathrm{At} \mathrm{present,} \mathrm{the} \mathrm{debate} \mathrm{about} \mathrm{active}$ sites continues.

\subsection{NiFe-based nitrides and phosphides and sulphides on nickel foam for OER}

Since the industrial-scale manufacturing of precious metal electrocatalysts is limited by their low natural reserves and high costs, transition metal nitrides, phosphides and sulphides have attracted much attention because of their excellent catalytic ability. Recently, much attention has been paid to develop efficient NiFe-based nitrides, phosphides and sulphides electrocatalysts.

\subsubsection{NiFe-based nitrides on nickel foam for OER}

Metal nitrides such as $\mathrm{Ni}_{3} \mathrm{FeN}$ nanoparticles and $\mathrm{Ni}_{3} \mathrm{~N}$ nanosheets have been proved to possess faster change-carrier transportation and better conductivity than metal oxide [107,108]. Thus, they are believed to be promising candidate electrocatalysts for OER. In 2016, Zhang et al. reported an in-situ growth of iron-nickel nitride nanostructures on nickel foam $\left(\mathrm{FeNi}_{3} \mathrm{~N} / \mathrm{NF}\right)$ by surface redox etching for the first time [109]. In the synthesis process, the nickel foam not only acted as the substrate but also served as a slow-releasing $\mathrm{Ni}$ precursor that was induced by redox etching of $\mathrm{Fe}$ precursor $\left(\mathrm{Fe}^{3+}\right)$ (Fig. 4(a)). The catalysts obtained by this method have stronger adhesion with the nickel foam substrate and can withstand larger electric currents (Fig. 4(b)). 

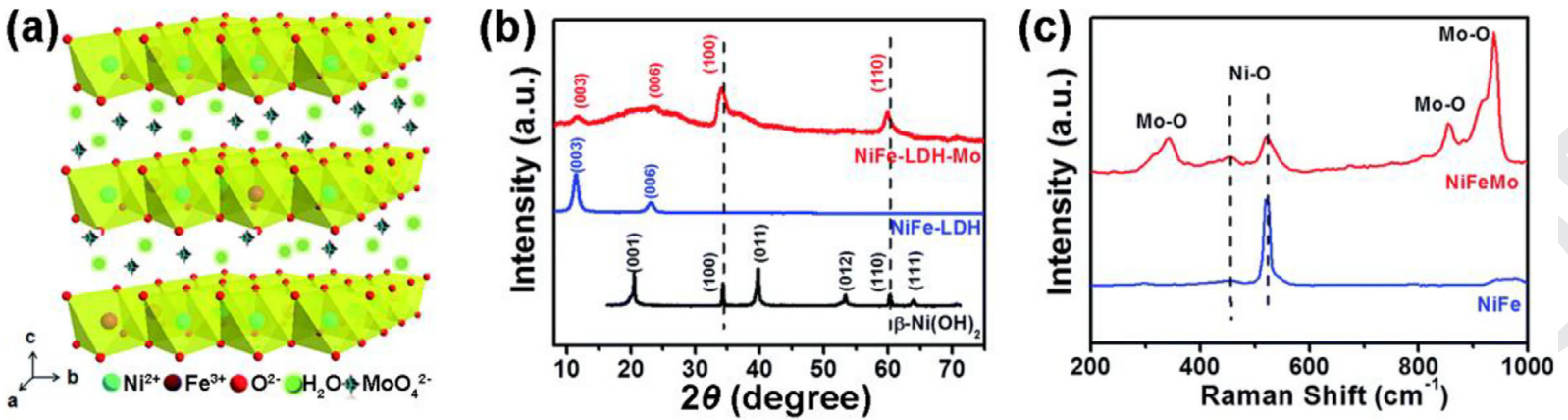

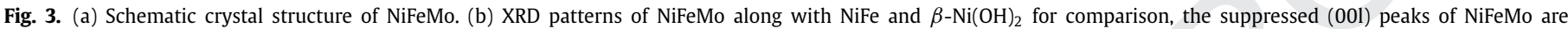
indicative of ultrathin nanosheet thickness. (c) Raman spectra of NiFeMo and NiFe showing the fingerprint vibrations of $\mathrm{Ni}_{-} \mathrm{OH}$ and $\mathrm{MoO}_{4}{ }^{2-}[102]$.
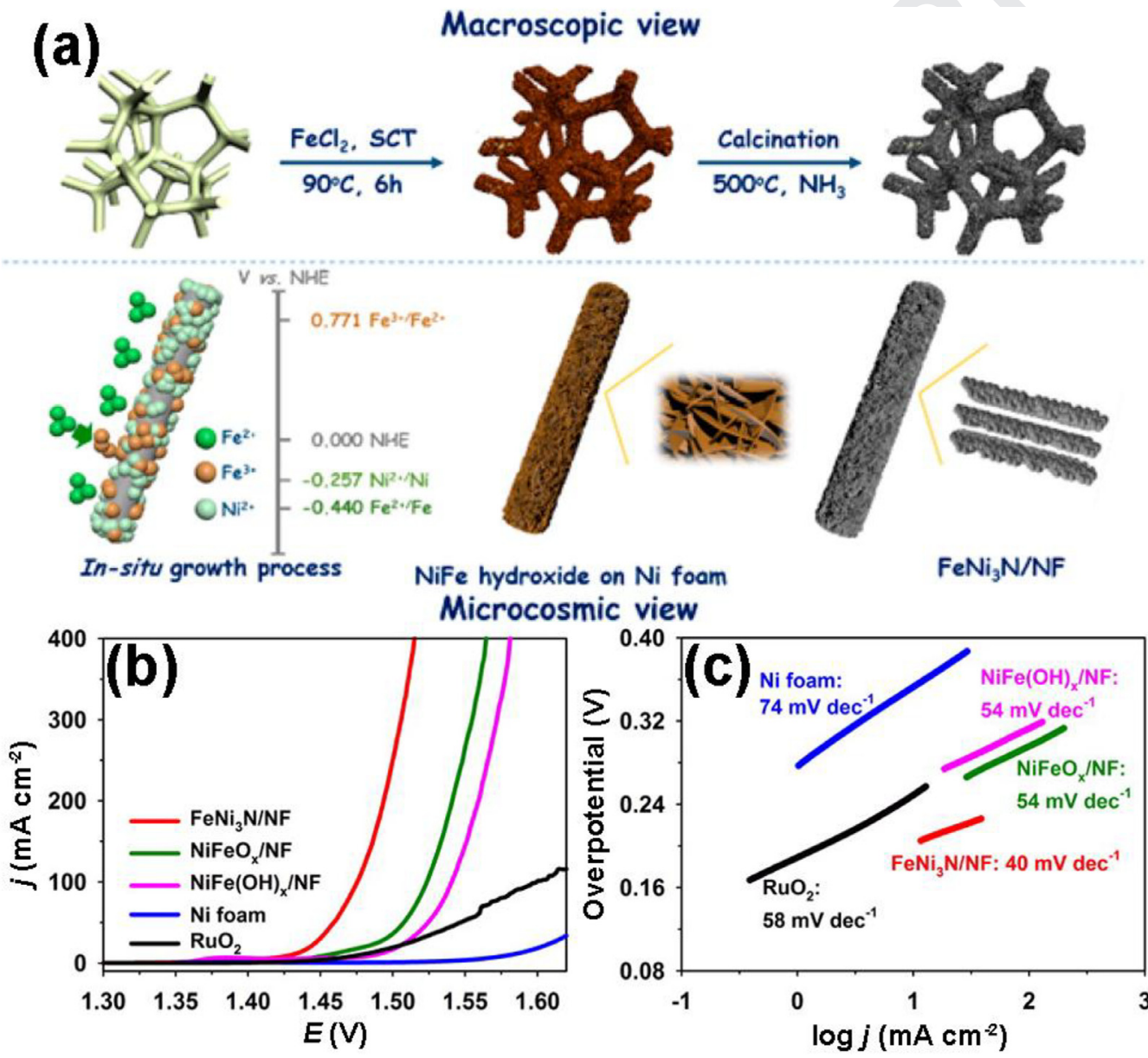

$\mathrm{FeNi}_{3} \mathrm{~N} / \mathrm{NF}$

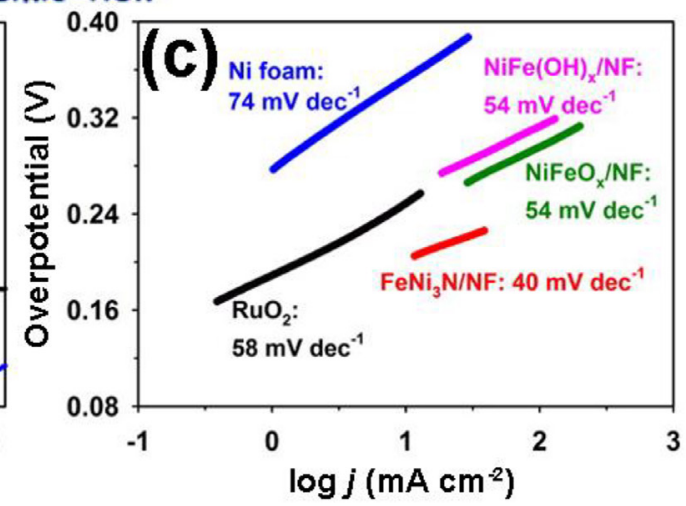

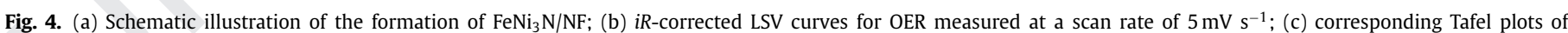
different materials [109].

For instance, the $\mathrm{FeNi}_{3} \mathrm{~N} / \mathrm{NF}$ has almost no attenuation stability over $30 \mathrm{~h}$ at a large current density of $100 \mathrm{~mA} \mathrm{~cm}-2$. As shown in Fig. 4(c), the Tafel slope of $\mathrm{FeNi}_{3} \mathrm{~N} / \mathrm{NF}\left(40 \mathrm{mV} \mathrm{dec}^{-1}\right)$ is much smaller than that of $\mathrm{RuO}_{2}\left(58 \mathrm{mV} \mathrm{dec}^{-1}\right)$. In addition, massive studies have shown that $\mathrm{N}$ doping can improve the catalytic performance of OER by improving the conductivity of the catalytic materials, such as $\mathrm{Co}_{4} \mathrm{~N}$ [110] and $\mathrm{N}-\mathrm{CoFe}$ LDHs [111]. Recently, Chen and co-workers reported that the surface $\mathrm{N}$ atoms of $\mathrm{Ni}_{3} \mathrm{~S}_{2}$ could regulate the electronic structure and then optimize the adsorption energy of active sites. Thus, the OER performance of $\mathrm{Ni}_{3} \mathrm{~S}_{2}$ has been greatly improved [112]. In such circumstances, Jin and co-workers developed a facile one-step method to fabricate the $\mathrm{N}-(\mathrm{Ni}, \mathrm{Fe})_{3} \mathrm{~S}_{2} / \mathrm{NIF}$ (NIF is $\mathrm{Ni}-\mathrm{Fe}$ alloy foam) as efficient OER catalyst [113]. The obtained $\mathrm{N}-(\mathrm{Ni}, \mathrm{Fe})_{3} \mathrm{~S}_{2} / \mathrm{NIF}$ catalyst has a low 398 overpotential of $167 \mathrm{mV}$ at $10 \mathrm{~mA} \mathrm{~cm}^{-2}$, which exhibits the best 399 OER performance so far. The authors attributed such superior 400 OER performance to the surface $\mathrm{N}$-anion decoration, because 401 the decorated $\mathrm{N}$ atoms could increase the density of states near 402 the Fermi level, and then enhance the electrical conductivity of 403 $(\mathrm{Ni}, \mathrm{Fe})_{3} \mathrm{~S}_{2} / \mathrm{NIF}$. The stability at high current density of NiFe-based 404 nitrides on nickel foam was reported by Duan's group in 2016405 [114]. The $\mathrm{Fe}_{2} \mathrm{Ni}_{2} \mathrm{~N}$ on nickel foam was synthetized through two 406 steps: the NiFe-LDH by simple hydrothermal method and then the 407 $\mathrm{Fe}_{2} \mathrm{Ni}_{2} \mathrm{~N}$ from NiFe-LDH under the reaction with $\mathrm{NH}_{3}$. The $\mathrm{Fe}_{2} \mathrm{Ni}_{2} \mathrm{~N} 408$ catalyst are both active in OER and HER. For instance, the OER 409 activity is much better than $\operatorname{Ir} / C$ and the HER activity is closed

00


(a)
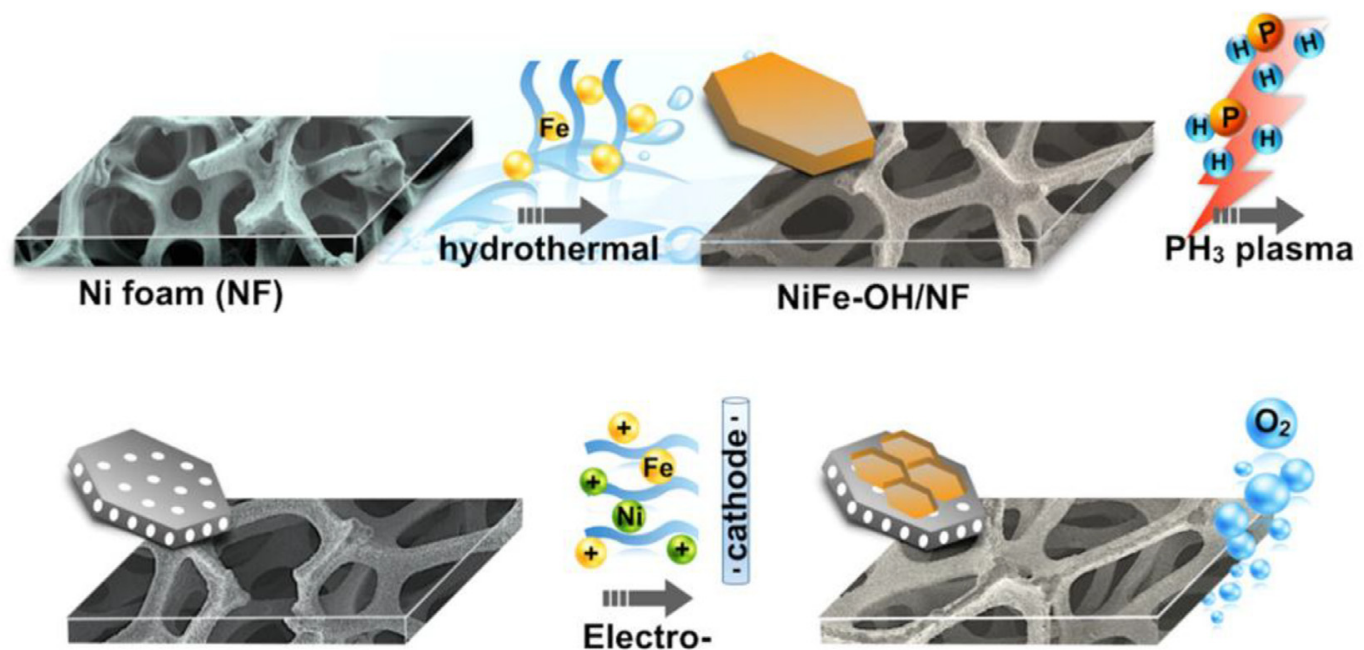

$\mathrm{NiFeP/NF}$
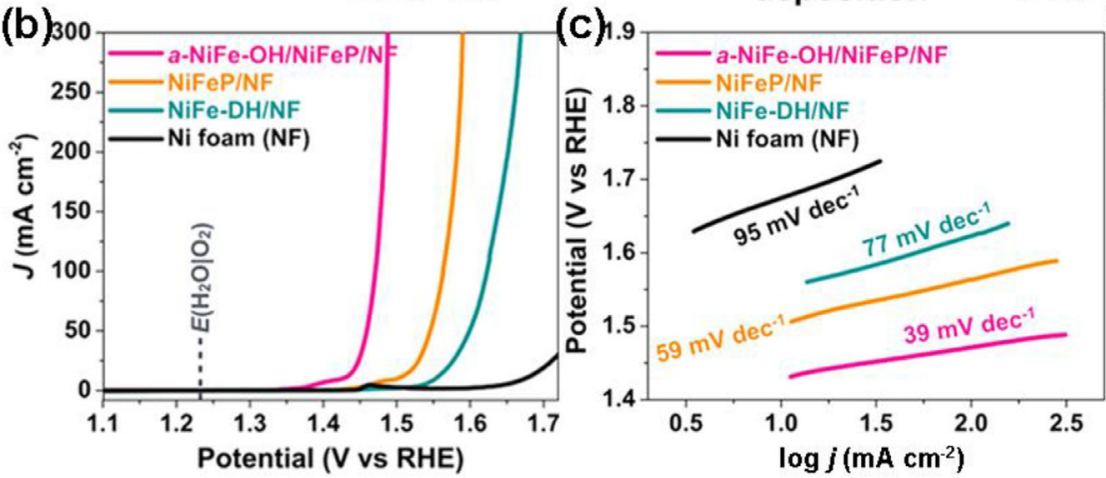

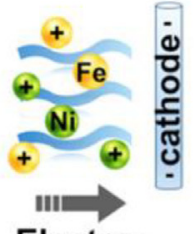

Electrodeposition

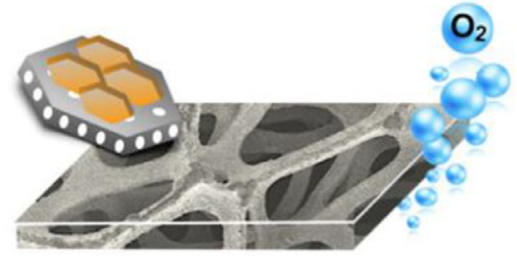

a-NiFe-OH/NiFeP/NF

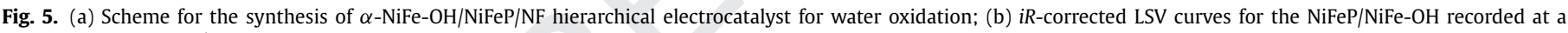

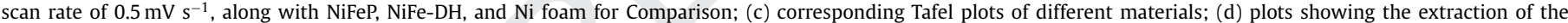
double-layer capacitances allow the estimation of the electrochemically active surface area (ECSA) [122].

to Pt on nickel foam. Combining with the super stability, such catalyst would be a potential candidate for It/C and Pt in WS.

\subsubsection{NiFe-based phosphides on nickel foam for OER}

Like metal nitrides, the metal phosphides are also developed as potential OER catalysts. The introduction of phosphorus not only enhances the conductivity of some metal catalysts, but also tunes the adsorption energy of active sites [115]. However, the enhanced OER performance of metal phosphides is still far from the best performance of the noble metal, such as FeP [116-118] and NiP $[16,119]$. To solve this issue, $\mathrm{Li}$ and co-workers reported the synthesis of Fe-doped $\mathrm{Ni}_{2} \mathrm{P}$ nanosheets on nickel foam [120]. The $\left(\mathrm{Ni}_{0.33} \mathrm{Fe}_{0.67}\right)_{2} \mathrm{P}$ electrode shows the best OER performance with overpotential of $\sim 230 \mathrm{mV}$ at $50 \mathrm{~mA} \mathrm{~cm}^{-2}$. In addition, the thickness of $\left(\mathrm{Ni}_{0.33} \mathrm{Fe}_{0.67}\right)_{2} \mathrm{P}$ nanosheets decreases from $\sim 40 \mathrm{~nm}$ to $\sim 20 \mathrm{~nm}$ with the introduction of $\mathrm{Fe}$, which suggests that the doped Fe atoms can not only regulate the electronic structure, but also affect the morphology of the catalyst. In 2017, Wang and coworkers also reported the preparation of Fe-doped $\mathrm{Ni}_{2} \mathrm{P}$ on nickel foam [121], where the amount of Fe was precisely controlled. Through the inductively coupled plasma atom emission spectrometry (ICP-AES) analysis, the authors confirmed that the Fe-doped $\mathrm{Ni}_{2} \mathrm{P}$ with the best OER performance is $\mathrm{Ni}_{185} \mathrm{Fe}_{0.15} \mathrm{P}$. The results show that the OER performance of $\mathrm{Ni}_{2} \mathrm{P}$ can be improved significantly with only about $8 \%$ Fe doping. However, the role of such trace Fe has not been discussed further in this paper. Therefore, there is still a lot of work need to be carried out to clarify the role of doped trace Fe. In addition to regulating the amount of doped $\mathrm{Fe}$, surface modification of NiFeP is a very effective way to improve the properties of OER. An NiFe-OH/NiFeP electrocatalyst on nickel foam for OER was reported by Liang et al. [122]. In order to further improve the OER performance of NiFeP, the authors deposited another layer of $a-\mathrm{NiFe}-\mathrm{OH}$ on NiFeP (Fig. 5(a)). The obtained NiFe-OH/NiFeP achieves a large current density of $300 \mathrm{~mA} \mathrm{~cm}^{-2}$ at a low overpotential (258 mV) (Fig. 5(b)), a low

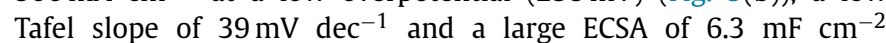
(Fig. 5(c) and (d)) in $1.0 \mathrm{M} \mathrm{KOH}$. The authors ascribed the enhanced OER performance to the strong electronic interactions between the deposited $\mathrm{NiFe}-\mathrm{OH}$ and NiFeP. Such intense electron interaction can significantly reduce the adsorption energy of $\mathrm{H}_{2} \mathrm{O}$ and lead to the enhanced OER performance. In 2017, Yu and co-workers reported an OER catalyst $\left(\left(\mathrm{Ni}_{0.5} \mathrm{Fe}_{0.5}\right)_{2} \mathrm{P}\right)$ with the good stability more than $24 \mathrm{~h}$ and studied the structure changes after the OER process [123]. The authors found that the metal phosphides disappeared and $\mathrm{Ni}-\mathrm{Fe}$ oxo/hydroxide species were generated after the OER test. They thought that the outstanding OER activity might be originated from Ni-Fe oxo/hydroxide. This phenomenon is also found on the NiFe-based nitrides and sulphides.

\subsubsection{NiFe-based sulphides on nickel foam for OER}

NiFe-based sulphides have many similarities in physicalchemical properties with NiFe-based phosphides, such as the strong metal-metalloid bonds (NiFe-P or NiFe-S) and the strong covalent metalloid-metalloid bonds (P-P or S-S) [124]. However, the application of NiFe-based sulphides on nickel foam in OER has not been explored before 2015. Cheng and co-workers reported the synthesis of Fe-doped $\mathrm{Ni}_{3} \mathrm{~S}_{2}$ particle film with $11.8 \%$ $\mathrm{Fe}$ on nickel foam $\left(\mathrm{Fe}_{11.8 \%}-\mathrm{Ni}_{3} \mathrm{~S}_{2} / \mathrm{NF}\right)$ for high-efficiency OER [125]. 

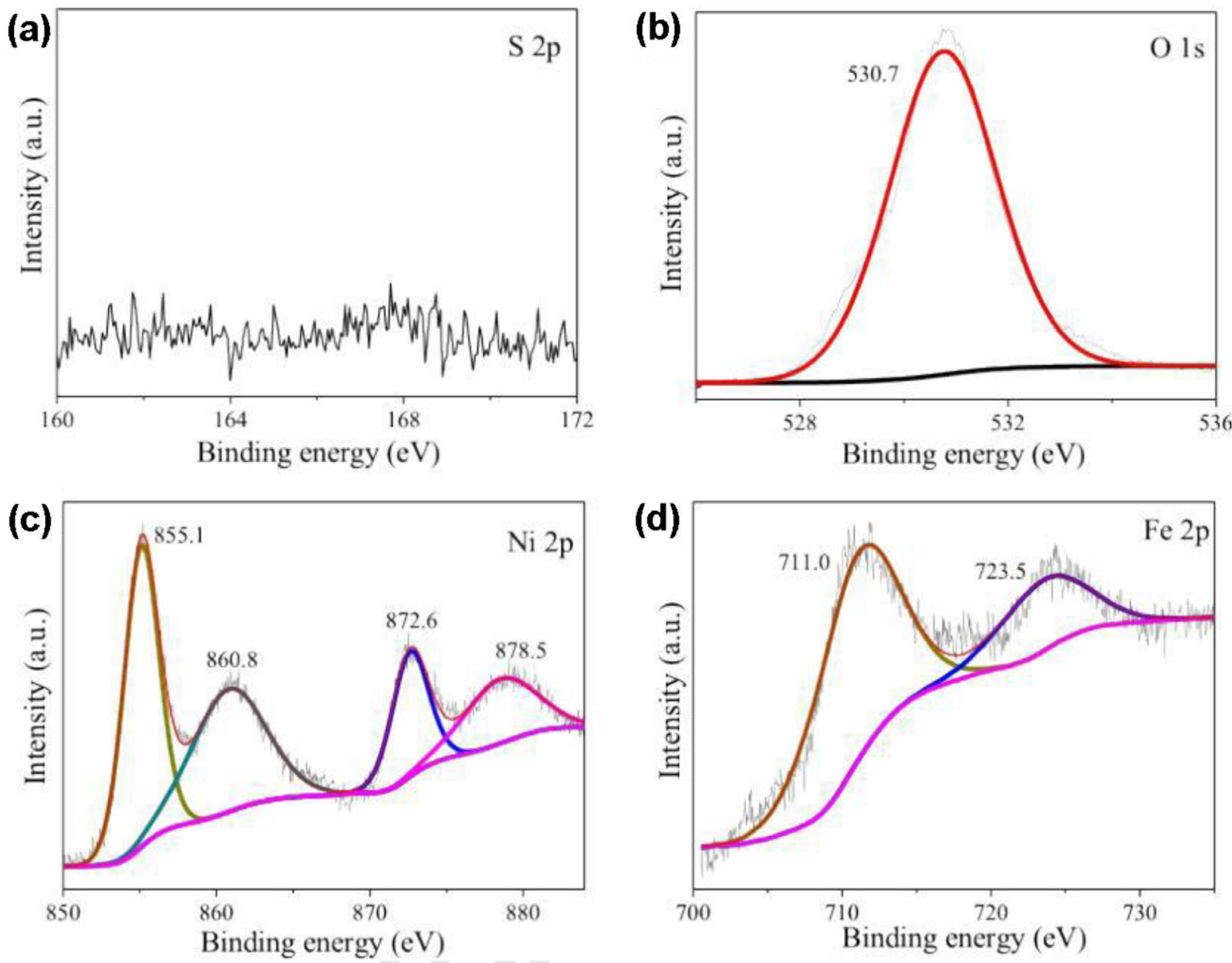

Fig. 6. XPS spectra (a) in the $\mathrm{S}(2 p)$ region; (b) in the $\mathrm{O}(1 s)$ region; (c) in the $\mathrm{Ni}(2 p)$ region and (d) in the $\mathrm{Fe}_{(2 p)} \mathrm{region}_{0} \mathrm{Ni} \mathrm{F}_{0.7} \mathrm{Fe}_{0.3} \mathrm{~S}_{2}$ after OER test [126].

The SEM image and TEM image reveal that the nickel foam is fully covered with $\mathrm{Fe}_{11.8 \%}-\mathrm{Ni}_{3} \mathrm{~S}_{2}$ particles and the diameters of $\mathrm{Fe}_{11.8 \%}-\mathrm{Ni}_{3} \mathrm{~S}_{2}$ particles are $400-800 \mathrm{~nm}$. The obtained $\mathrm{Fe}_{11.8 \%}-$ $\mathrm{Ni}_{3} \mathrm{~S}_{2} / \mathrm{NF}$ shows a lower overpotential of $253 \mathrm{mV}$ compared with the overpotential of $\mathrm{Ni}_{3} \mathrm{~S}_{2} / \mathrm{NF}(431 \mathrm{mV})$ when the current density reaches $100 \mathrm{~mA} \mathrm{~cm}^{-2}$ in $1.0 \mathrm{M} \mathrm{KOH}$. The XPS spectra and the Raman spectra of $\mathrm{Fe}_{11.8 \%}-\mathrm{Ni}_{3} \mathrm{~S}_{2} / \mathrm{NF}$ after OER confirm the formation of $\mathrm{NiOOH}$ and $\mathrm{FeOOH}$. These observations conclude that the $\mathrm{NiOOH}$ and $\mathrm{FeOOH}$ on $\mathrm{Fe}_{11.8 \%}-\mathrm{Ni}_{3} \mathrm{~S}_{2}$ surface are the true active phases for OER. Such change of chemical constitution was reported in by $\mathrm{Yu}$ and co-works. They synthesized the ternary nickel-iron sulfide as a robust electrocatalyst, $\mathrm{Ni}_{0.7} \mathrm{Fe}_{0.3} \mathrm{~S}_{2}$ [126]. The further characterization after the OER measurement shows that the Ni-Fe oxo/hydroxide species appear, indicating that the OER catalytic activity of $\mathrm{Ni}_{0.7} \mathrm{Fe}_{0.3} \mathrm{~S}_{2}$ might originate from the formation of Ni-Fe oxo/hydroxide species (Fig. 6). The more details of such phenomenon were discussed in 2016, in which Shanmugam's group reported an ultra-durable electrocatalyst through an inexpensive electrochemical synthesis [127]. The stability over $200 \mathrm{~h}$ of $\mathrm{Ni}_{2} \mathrm{FeS}_{4} / \mathrm{NF}$ (NF represents nickel foam) in $1.0 \mathrm{M} \mathrm{KOH}$ makes it possible to apply in the alkaline electrolyte membrane water electrolysis. The $\mathrm{Ni}_{2} \mathrm{FeS}_{4} / \mathrm{NF}$ was synthesized via chronoamperometry (Fig. 7(a)), and the reaction followed the following equations:

$\mathrm{Ni}^{2+}+2$ Thiourea $\rightarrow \mathrm{Ni}(\text { Thiourea })_{2}{ }^{2+}$

$\mathrm{Ni}$ (Thiourea) ${ }_{2}{ }^{2+}+\mathrm{NiFe} \rightarrow \mathrm{Ni}_{2} \mathrm{FeS}_{4}$

The $\mathrm{Ni}_{2} \mathrm{FeS}_{4}$ was obtained by the reduce of $\mathrm{Ni}$ (Thiourea) $)_{2}$ intermediate, and the thickness of coated $\mathrm{Ni}_{2} \mathrm{FeS}_{4}$ can be controlled by controlling deposition time. The OER activity of $\mathrm{Ni}_{2} \mathrm{FeS}_{4} / \mathrm{NF}$ with 492 deposited thickness of $2.71 \mu \mathrm{m}\left(\eta_{100}=231 \mathrm{mV}\right)$ is greater than 493 that of $\mathrm{Ni}_{3} \mathrm{~S}_{2} / \mathrm{NF}\left(\eta_{100}=400 \mathrm{mV}\right)$ and $\mathrm{RuO}_{2}\left(\eta_{100}=460 \mathrm{mV}\right)$ in 494 $1.0 \mathrm{M} \mathrm{KOH}$ (Fig. 7(b)). The low Tafel slope of $74 \mathrm{mV} \mathrm{cm}^{-2}$ in $1.0 \mathrm{M} 495$ $\mathrm{KOH}$ confirm the facile electrode kinetics (Fig. 7(c) and (d)). The 496 authors considered that this is owing to the emergence of a new 497 active phase during the reversible oxidation of NiFe sulphides to 498 NiFe oxy-sulphides. This phenomenon often occurred on metal 499 chalcogenides through the following reaction steps.

$\mathrm{M}_{\mathrm{cat}} \mathrm{OH}^{-} \rightarrow \mathrm{M}_{\mathrm{cat}} \mathrm{OH}^{-}+\mathrm{e}^{-}$

$\mathrm{M}_{\mathrm{cat}} \mathrm{OH}^{-}+\mathrm{OH}^{-} \rightarrow \mathrm{M}_{\mathrm{cat}} \mathrm{O}^{*}+\mathrm{H}_{2} \mathrm{O}$

$\mathrm{M}_{\mathrm{cat}} \mathrm{O}^{*} \rightarrow \mathrm{SO}+\mathrm{e}^{-}$

$2 \mathrm{SO} \rightarrow 2 \mathrm{~S}+\mathrm{O}_{2}$

The generated larger $\mathrm{S}$ atoms in the $\mathrm{Ni}_{2} \mathrm{FeS}_{4} / \mathrm{NF}$ could adsorb more hydroxide ions, thus increasing the kinetics of the OER reaction.

501

\section{NiFe-based electrocatalysts on nickel foam for HER}

HER has received a lot of attention recently as another important half reaction in WS. It plays an important role in contemporary clean-energy revolution, such as proton exchange membrane (PEM) [128-130], chlor-alkali electrolyzers [131], water-alkali electrolyzers [132] and solar water-splitting devices [2,133]. However, the large overpotential and the high requirement of non-noble metal catalyst in the electrolyte restricted its practical applications. It is difficult to develop a HER catalyst that is both efficient and 
(a)
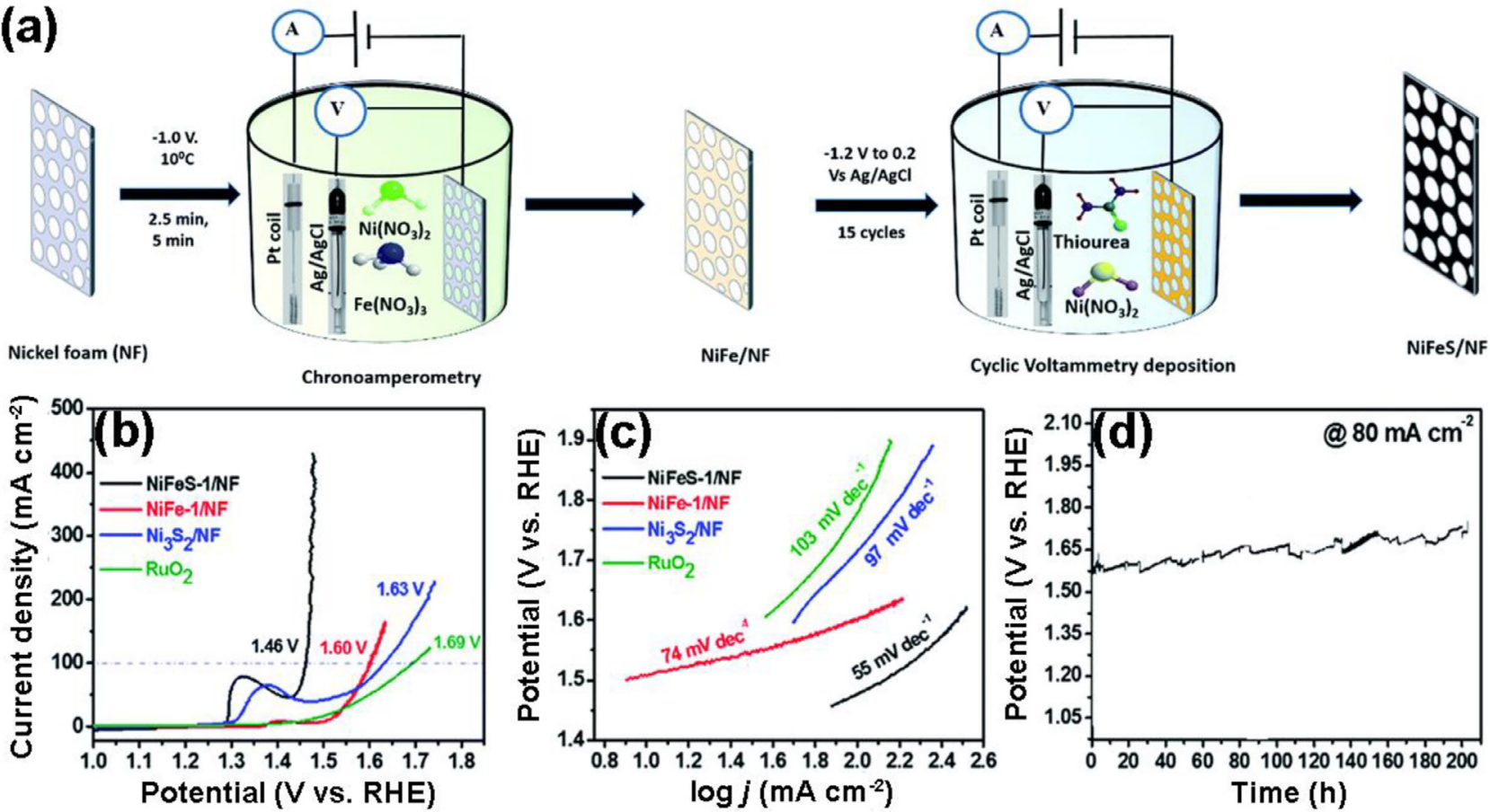

$\mathrm{NiFe} / \mathrm{NF}$

Cyclic Voltammetry deposition

NiFeS/NF
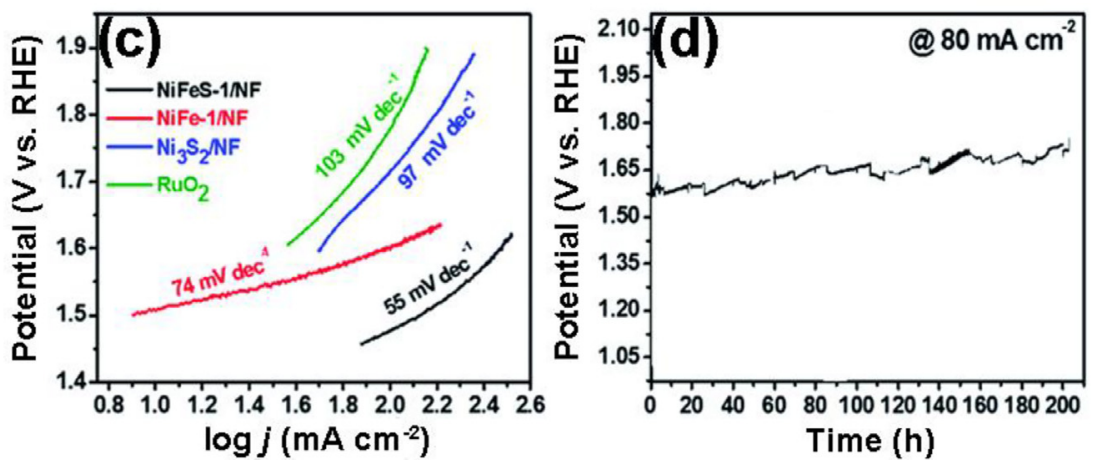

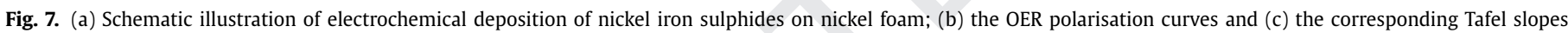
of $\mathrm{NiFeS}-1 / \mathrm{NF}, \mathrm{NiFe}-1 / \mathrm{NF}, \mathrm{Ni}_{3} \mathrm{~S}_{2} / \mathrm{NF}$ and $\mathrm{RuO}_{2}$; (d) OER chronopotentiometric durability of NiFeS-1/NF [127].

Table 3. The performance of the NiFe-based electrocatalysts in HER.

\begin{tabular}{|c|c|c|c|c|c|}
\hline Catalyst/nickel foam & Electrolyte & $\eta$ at $\mathrm{x} \mathrm{mA} \mathrm{cm}-2(\mathrm{mV})$ & Tafel slope (mV dec $\left.{ }^{-1}\right)$ & Stability & Ref. \\
\hline \multirow[t]{2}{*}{ NiFeP } & $0.5 \mathrm{H}_{2} \mathrm{SO}_{4}$ & $\eta_{100}=185$ & 64.6 & More than $12 \mathrm{~h}$ at $10 \mathrm{~mA} \mathrm{~cm}-2$ & \multirow[t]{2}{*}{ [139] } \\
\hline & $1.0 \mathrm{KOH}$ & $\eta_{100}=247$ & 84.24 & More than $12 \mathrm{~h}$ at $10 \mathrm{~mA} \mathrm{~cm}-2$ & \\
\hline NiFe-P & $1.0 \mathrm{KOH}$ & $\eta_{200}=355$ & 48 & More than $12 \mathrm{~h}$ & [142] \\
\hline $\mathrm{FeNiP}_{x}$ & $1.0 \mathrm{KOH}$ & $\eta_{100}=161$ & 80 & More than $90 \mathrm{~h}$ at $50 \mathrm{~mA} \mathrm{~cm}-2$ & [143] \\
\hline $\mathrm{Fe}-\mathrm{Ni}_{3} \mathrm{~S}_{2}$ & $1.0 \mathrm{KOH}$ & $\eta_{100}=232$ & 95 & More than $20 \mathrm{~h}$ at $173 \mathrm{~mA} \mathrm{~cm}^{-2}$ & [150] \\
\hline FeNi-S film & $1.0 \mathrm{KOH}$ & $\eta_{100}=186$ & 77 & More than $10,000 \mathrm{~s}$ & [152] \\
\hline \multirow[t]{3}{*}{$\left(\mathrm{Fe}_{0.048} \mathrm{Ni}_{0.952}\right)_{2} \mathrm{P}$} & $0.5 \mathrm{H}_{2} \mathrm{SO}_{4}$ & $\eta_{50}=126$ & 41.6 & More than $10 \mathrm{~h}$ at $50 \mathrm{~mA} \mathrm{~cm}^{-2}$ & \multirow[t]{3}{*}{ [69] } \\
\hline & $1.0 \mathrm{KOH}$ & $\eta_{50}=162$ & 76.6 & More than $20 \mathrm{~h}$ at $100 \mathrm{~mA} \mathrm{~cm}-2$ & \\
\hline & 1.0 PBS & $\eta_{50}=169$ & 82.7 & More than $20 \mathrm{~h}$ at $100 \mathrm{~mA} \mathrm{~cm}^{-2}$ & \\
\hline
\end{tabular}

stable. On the other side, as the best reactive condition for OER is in alkaline medium, for ideal WS, HER should also have excellent HER performance in alkaline medium. However, due to that the electric conductance $(G=1 / R)$ of $\mathrm{H}_{2} \mathrm{SO}_{4}$ is greater than that of $\mathrm{KOH}$ and phosphate buffer solution (PBS) [134], the developed HER electrocatalysts are more active in acidic medium than in alkaline and neutral medium. Herein, we summarize the NiFe-based electrocatalysts from different electrolytes (Table 3 ).

\subsection{NiFe-based electrocatalysts on nickel foam for HER in acidic electrolytes}

Towards the electrocatalysts based on nickel foam, acidic electrolyte is unfavorable to them because long-term soaking will corrode the nickel foam, leading to bad stability. Nevertheless, some catalysts on nickel foam were found to be durable in the acidic media within a certain voltage range. Chen's group reported that the nickel foam could stay stable more than 5 days for HER in $0.5 \mathrm{M}$ $\mathrm{H}_{2} \mathrm{SO}_{4}$. This is because the metallic $\mathrm{Ni}$ will be passivated to the unsolvable $\mathrm{Ni}_{2} \mathrm{SO}_{4}$ under $0.5 \mathrm{M} \mathrm{H}_{2} \mathrm{SO}_{4}$ at a suitable overpotential following the equation [135]:

$2 \mathrm{Ni}+\mathrm{H}_{2} \mathrm{SO}_{4}=\mathrm{Ni}_{2} \mathrm{SO}_{4}+\mathrm{H}_{2}$

$\mathrm{Ni}+2 \mathrm{e}^{-} \rightarrow \mathrm{Ni}, \quad E^{\theta}=-0.246 \mathrm{~V}$

$2 \mathrm{H}^{+}+2 \mathrm{e}^{-}=\mathrm{H}_{2}$
The calculated results above showed that the nickel foam could 532 be stabilized under $0.5 \mathrm{M} \mathrm{H}_{2} \mathrm{SO}_{4}$ when the overpotential is greater than $-0.246 \mathrm{~V}$. The subsequent experiments also proved this finding $[136,137]$. In addition, the $\mathrm{Ni}_{2} \mathrm{P}$ nanosheets were successfully grown on nickel foam $\left(\mathrm{Ni}_{2} \mathrm{P} / \mathrm{Ni}\right)$ by Shi et al. The sample displays excellent HER performance at all $\mathrm{pH}$ values, and its stability under acidic condition is remarkable [138]. For instance, the stability of $\mathrm{Ni}_{2} \mathrm{P} / \mathrm{Ni}$ was tested at the overpotential of $-0.175 \mathrm{~V}$ for nearly $70 \mathrm{~h}$, and almost no decay was observed. In 2016, Wang's group reported the preparation of self-supported porous NiFeP nanocomposite as an efficient electrocatalyst via the direct reaction of $\mathrm{Ni}-\mathrm{Fe}$ foam and $\mathrm{P}$ vapor [139]. The obtained NiFeP shows the outstanding performance in both acidic $\left(0.5 \mathrm{M} \mathrm{H}_{2} \mathrm{SO}_{4}\right)$ and alkaline $(1.0 \mathrm{M} \mathrm{KOH})$ solution. For example, the NiFeP exhibits a low onset potential $(40 \mathrm{mV})$, and its overpotentials with current densities of 10 and $100 \mathrm{~mA} \mathrm{~cm} \mathrm{~cm}^{-2}$ are merely located at $89 \mathrm{mV}$ and $185 \mathrm{mV}$ in $0.5 \mathrm{M} \mathrm{H}_{2} \mathrm{SO}_{4}$ (Fig. $8(\mathrm{a})$ ). The results are superior to those of the reported Ni-P foam $\left(\eta_{10}=120 \mathrm{mV}\right.$ and $\left.\eta_{100}=200 \mathrm{mV}\right)$. Besides, the Tafel slope $\left(64.6 \mathrm{mV} \mathrm{cm} \mathrm{cm}^{-2}\right)$ of NiFeP is only barely inferior to that of $\mathrm{Pt} / \mathrm{C}\left(30.8 \mathrm{mV} \mathrm{cm}^{-2}\right)$ in $0.5 \mathrm{M} \mathrm{H}_{2} \mathrm{SO}_{4}$. In addition, the NiFeP shows the excellent HER performance in $1.0 \mathrm{M} \mathrm{KOH}$ (Fig. 8(b)). The onset potential is located at $75 \mathrm{mV}$, which is much close to that of Pt/C. The $\eta_{10}, \eta_{50}$ and $\eta_{100}$ of NiFeP are $142 \mathrm{mV}$, $212 \mathrm{mV}$ and $247 \mathrm{mV}$, respectively, which are better than that of $\mathrm{Ni}-$ Fe foam and Ni foam (Fig. 8(c)). As shown in Fig. 8(d), the NiFeP 

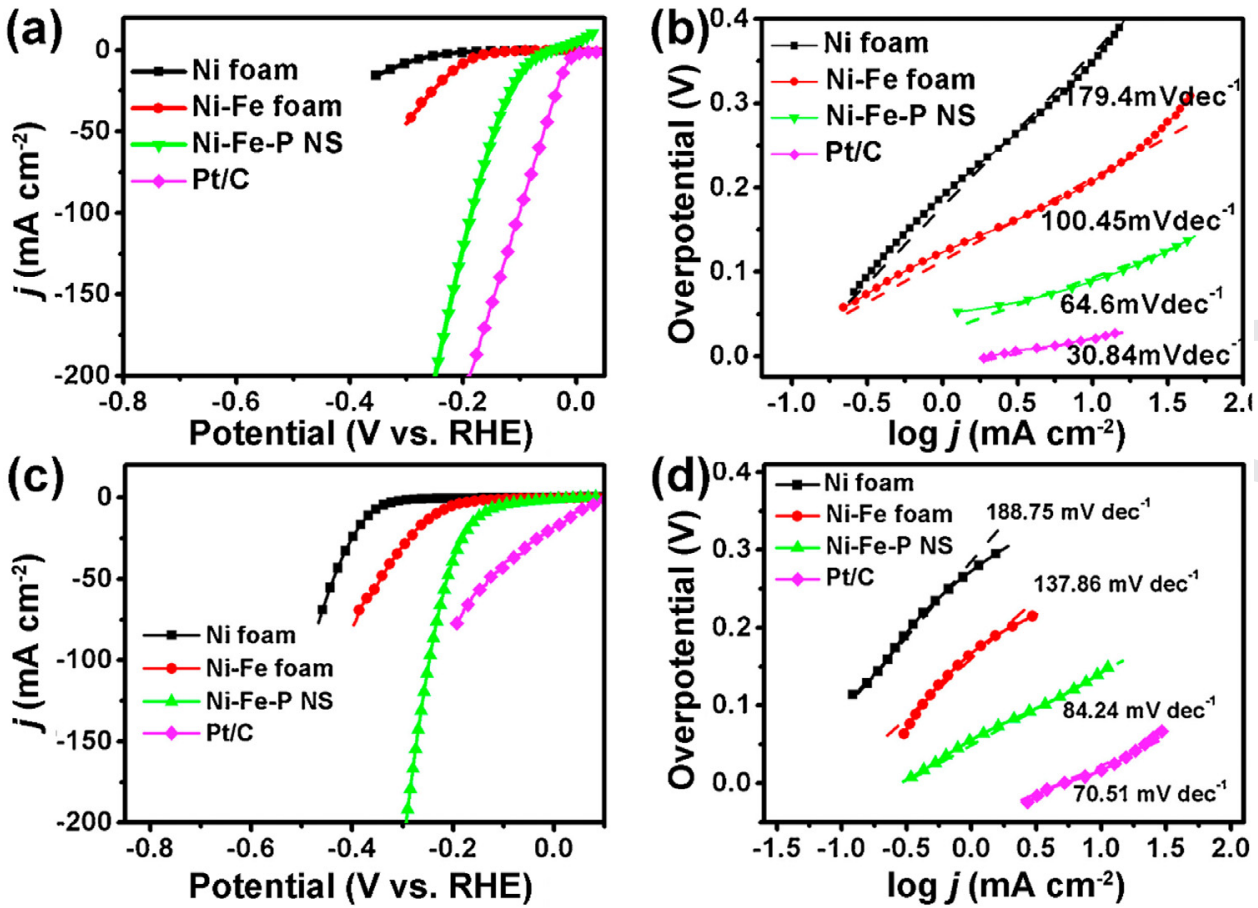

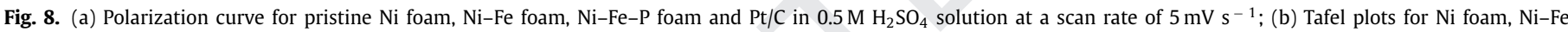

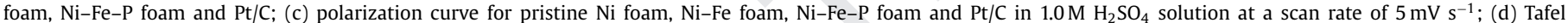
plots for Ni foam, Ni-Fe foam, Ni-Fe-P foam and Pt/C [139].

also shows small Tafel slope $\left(84.24 \mathrm{mV} \mathrm{cm}^{-2}\right)$ in $1.0 \mathrm{M} \mathrm{KOH}$, suggesting that the Volmer-Heyrovsky mechanism occurs during HER process.

\subsection{NiFe-based electrocatalysts on nickel foam for HER in alkaline electrolytes}

Although the NiFe-LDH and the other NiFe oxides show the unsatisfied catalytic performance towards HER in alkaline electrolytes, the NiFe compounds, such as NiFeP [140], NiFeS [141] and NiFeN [5], present the unexpected excellent HER performances. Xing et al. reported the synthesis of porous Ni-Fe phosphate film on nickel foam (NiFe-P/NF) [142], and the NiFe-P/NF presents remarkable HER performance $\left(\eta_{10}=87 \mathrm{mV}\right.$ and $\left.\eta_{200}=355 \mathrm{mV}\right)$ in 1.0 M KOH. As shown in Fig. 11(a), the SEM image shows that a film of active materials could be observed on nickel foam, and many nanoparticles could be seen on top of the film. The similar surface feature occurs on Ni-P film on nickel foam (Ni-P/NF) (Fig. 9), but the $\eta_{200}$ of $\mathrm{Ni}-\mathrm{P} / \mathrm{NF}$ is $384 \mathrm{mV}$, which is larger than that of NiFe-P/NF. The Tafel slope of NiFe-P/NF is $48 \mathrm{mV} \mathrm{dec}^{-1}$, which is much lower than that of $\mathrm{Ni}-\mathrm{P} / \mathrm{NF}\left(90 \mathrm{mV} \mathrm{dec}^{-1}\right)$. These results indicated that the introduction of $\mathrm{Fe}$ into $\mathrm{Ni}-\mathrm{P} / \mathrm{NF}$ could facilitate electron transportation and thereby enhance the HER activity. In 2017, Xiao and co-workers used nickel foam as substrate and $\mathrm{Ni}$ source to fabricate $\mathrm{FeNiP}_{x} / \mathrm{NF}$ (NF represents nickel foam) catalysts for HER [143]. Benefiting from advantages of bimetallic composite and nickel foam, the $\mathrm{FeNiP}_{X} / \mathrm{NF}$ catalyst exhibits low overpotentials of $106 \mathrm{mV}$ at $10 \mathrm{~mA} \mathrm{~cm}^{-2}$ and $161 \mathrm{mV}$ at $100 \mathrm{~mA} \mathrm{~cm}{ }^{-2}$, respectively. Significantly, the $\mathrm{FeNiP}_{x} / \mathrm{NF}$ shows larger current density compared with the most catalysts on conductive substrate, such as $\mathrm{FeCO}_{2} \mathrm{~S}_{4}$ on nickel foam, Fe-doped $\mathrm{CoP}$ on $\mathrm{Ti}$ foil and $\mathrm{NiO}$ on $\mathrm{Ni}$ film [144-146]. The authors declared that this is due to that the newly etched $\mathrm{Ni}$ ions from nickel foam can be in-situ deposited, which makes the combination of $\mathrm{FeNiP}_{x}$ and nickel foam more stable and enhances the stability of $\mathrm{FeNiP}_{x} / \mathrm{NF}$ during the process of
HER. Nearly $400 \mathrm{~h}$ of stability testing at $50 \mathrm{~mA} \mathrm{~cm}-2$ was carried out to confirm the advantage of this in-situ deposited method.

$\mathrm{Ni}$ sulfides have drawn much attention to HER due to their low cost and facile fabrication [130], and several works about $\mathrm{Ni}$ sulfides on nickel foam have been reported, such as $\mathrm{Ni}$ sulfide nanosheets on nickel foam (NiS/NF) and porous $\mathrm{Ni}$ sulfide on nickel foam $\left(\mathrm{NiS}_{X} / \mathrm{NF}\right)[147,148]$. The overpotentials at $10 \mathrm{~mA} \mathrm{~cm}-2$ of $\mathrm{NiS} / \mathrm{NF}$ and $\mathrm{NiS}_{X} / \mathrm{NF}$ are $112 \mathrm{mV}$ and $60 \mathrm{mV}$, respectively. Fe doping has been well established as an effective strategy by optimizing electronic structure to further improve the HER activity of Ni sulfides [149]. For instance, Zhang et al. found that the electrocatalytic performance could be enhanced by Fe doping in $\mathrm{Ni}_{3} \mathrm{~S}_{2}$ nanosheets on nickel foam in 2018 [150]. The $\mathrm{Fe}-\mathrm{Ni}_{3} \mathrm{~S}_{2}$ catalyst was obtained by a facile two-step strategy and the $\mathrm{Fe}-\mathrm{Ni}_{3} \mathrm{~S}_{2}$ nanosheets grown vertically on nickel foam (Fig. 10(a)). It should be pointed out that there was the extra electron transfer to $S$ atoms after Fe doping according XPS of $\mathrm{Fe}_{17.5 \%}-\mathrm{Ni}_{3} \mathrm{~S}_{2}$ (Fig. 10(b)). This could change the electronic structure of $\mathrm{Fe}_{17.5 \%}-\mathrm{Ni}_{3} \mathrm{~S}_{2}$ and enhance the HER performance. Then the authors calculated the value of adsorption free energy of $\mathrm{H}^{*}\left(\Delta G_{\mathrm{H}^{*}}\right)$ of $\mathrm{Fe}_{17.5 \%}-\mathrm{Ni}_{3} \mathrm{~S}_{2}$ on $\mathrm{S}$-ended surface and Ni-ended surface, respectively. All the values of $\Delta G_{\mathrm{H}^{*}}$ are closed to thermoneutral energy compared with that of $\mathrm{Ni}_{3} \mathrm{~S}_{2}$, indicating that the Fe doping can optimize the adsorption of $\mathrm{H}^{*}$ on active sites and reduce the reaction energy barrier. The electrochemical performances of $\mathrm{Fe}_{17.5 \%}-\mathrm{Ni}_{3} \mathrm{~S}_{2} / \mathrm{NF}$ were consistent with the above calculated results, and the overpotentials of $\mathrm{Fe}_{17.5 \%}-$ $\mathrm{Ni}_{3} \mathrm{~S}_{2} / \mathrm{NF}$ at 10,20 and $100 \mathrm{~mA} \mathrm{~cm} \mathrm{~cm}^{-2}$ were 47,142 and $232 \mathrm{mV}$, respectively (Fig. 10(c)). The authors also calculated the Tafel slope of the $\mathrm{Fe}_{17.5 \%}-\mathrm{Ni}_{3} \mathrm{~S}_{2} / \mathrm{NF}$, and the low value $\left(95 \mathrm{mV} \mathrm{dec}{ }^{-1}\right)$ represented the fast reaction kinetics (Fig. 10(d)). In order to confirm whether the real active sites changed during the HER process. The authors used XPS measurement coupled with $\mathrm{Ar}^{+}$sputtering technique to analyze the changes of $\mathrm{Fe}_{17.5 \%}-\mathrm{Ni}_{3} \mathrm{~S}_{2} / \mathrm{NF}$ after the longterm HER process. No obvious change has been observed, which was a good proof that the $\mathrm{Fe}_{17.5 \%}-\mathrm{Ni}_{3} \mathrm{~S}_{2} / \mathrm{NF}$ has always maintained the same composition during HER. This work confirmed that the 

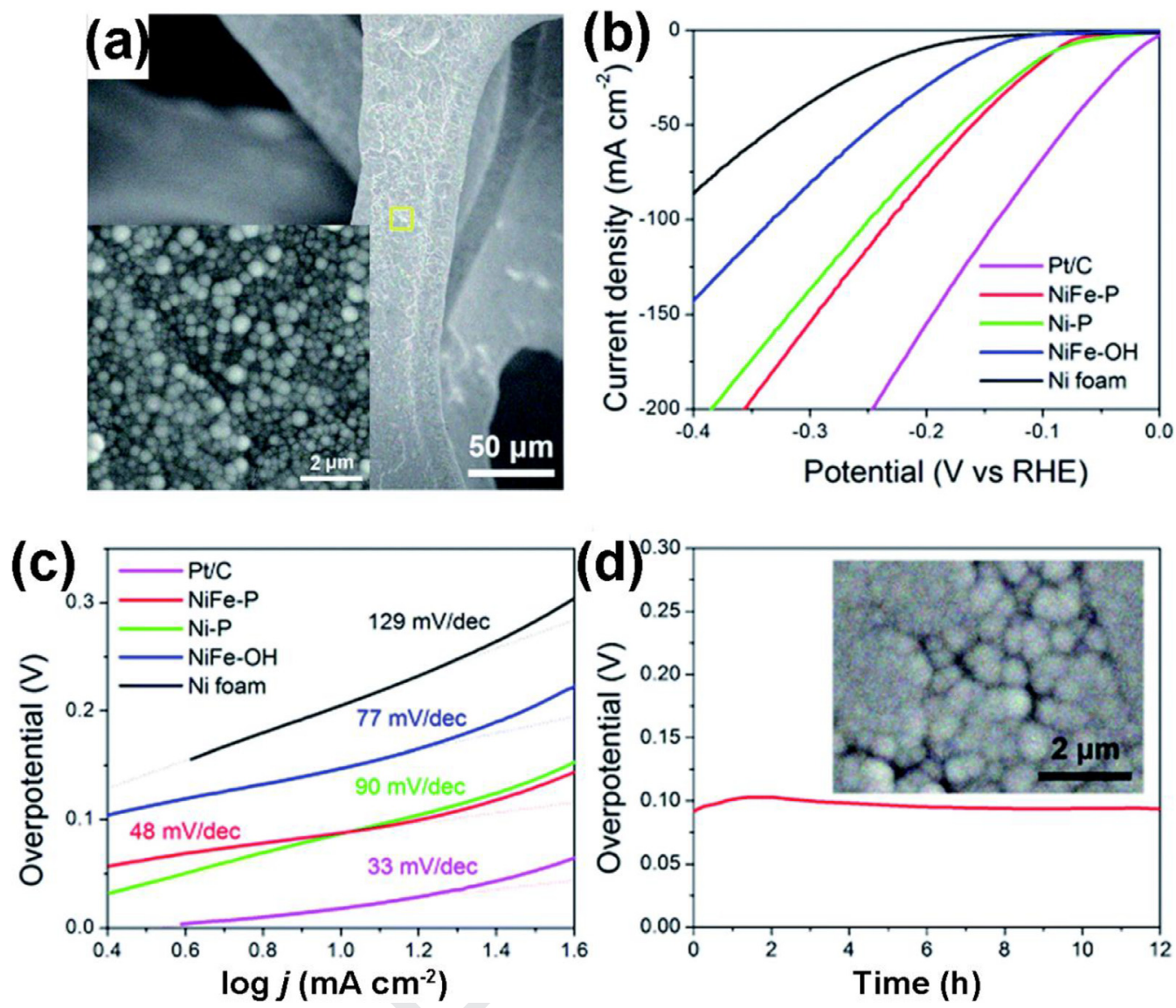

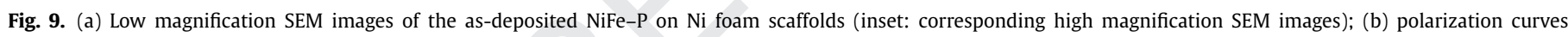
obtained in $1.0 \mathrm{M} \mathrm{KOH}$ and (c) corresponding Tafel slopes; (d) chronopotentiometric curves of NiFe-P at $0.1 \mathrm{~V}$ for $12 \mathrm{~h}$ (inset:) [142].
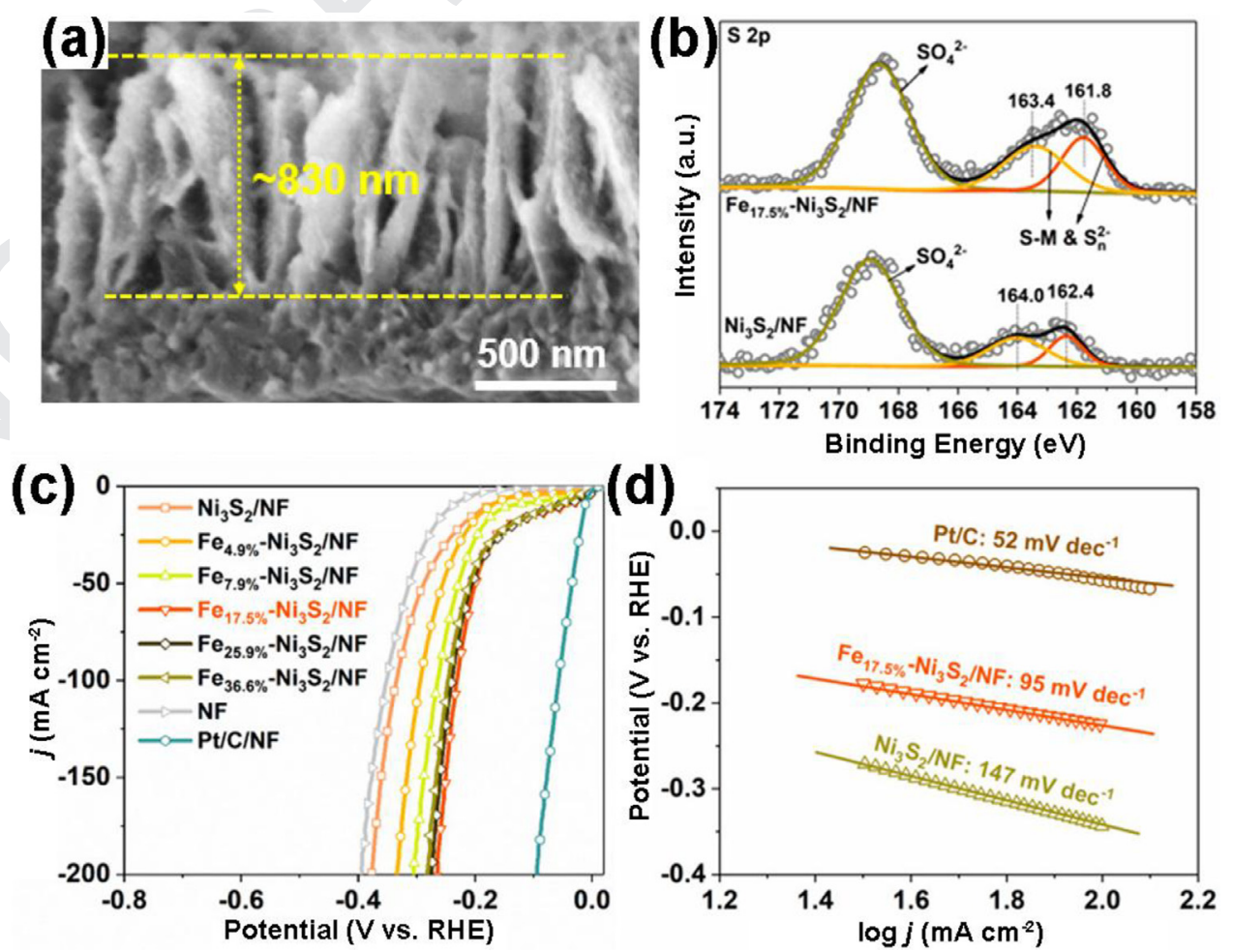

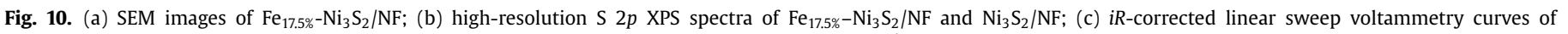
$\mathrm{Fe}-\mathrm{Ni}_{3} \mathrm{~S}_{2} / \mathrm{NF}$ with various Fe doping levels, $\mathrm{Ni}_{3} \mathrm{~S}_{2} / \mathrm{NF}$, and Pt/C/NF for HER in $1.0 \mathrm{M} \mathrm{KOH}$ at $5 \mathrm{mV} \mathrm{s}^{-1}$; (d) Tafel plots for Fe $17.5 \%-\mathrm{Ni}_{3} \mathrm{~S}_{2} / \mathrm{NF}, \mathrm{Ni}_{3} \mathrm{~S}_{2} / \mathrm{NF}$, and Pt/C/NF $[150]$. 
Fe doping can enhance the HER performance of $\mathrm{Ni}_{3} \mathrm{~S}_{2}$ from experiment and theory calculation, and the active sites of $\mathrm{Fe}_{17.5 \%-}$ $\mathrm{Ni}_{3} \mathrm{~S}_{2} / \mathrm{NF}$ are stable in HER.

The surface morphology of the electrocatalysts is another key parameter for efficient HER, and such advantageous surface morphology will expose more active sites and obtain the excellent catalytic performance. However, it is a challenge to tune the morphology in a facile way [151]. Shang and co-works successfully tuned the morphology of FeNi-S film on nickel foam by liquid crystal template (LCT) [152]. The existence of LCT could lead to the porous FeNi-S film with high surface area, which could expose more active sites and lead to an excellent catalytic performance. Compared with the overpotential of nonporous $\mathrm{Fe}-\mathrm{Ni}-\mathrm{S}$ film without LCT $(178 \mathrm{mV})$ at the current density of $10 \mathrm{~mA} \mathrm{~cm}^{-2}$, the overpotential at the current density of $10 \mathrm{~mA} \mathrm{~cm}{ }^{-2}$ of Fe-Ni-S film (LCT) is only $47 \mathrm{mV}$. This method might provide a facile strategy by tuning catalytic morphology to obtain highly active catalysts for HER.

\subsection{NiFe-based electrocatalysts on nickel foam for HER under all $\mathrm{pH}$ electrolytes}

As the slow HER kinetics in neutral media, the studies of highly efficient neutral HER catalysts were relatively rare. We summarize some works on nickel foam applied for HER under all $\mathrm{pH}$ value here. Duan's group synthetized FeCoP on nickel foam through simple in situ phosphidation from FeCo-LDH [153]. The FeCoP shows excellent HER performance and long-time stability in different $\mathrm{pH}$ electrolytes $(\mathrm{pH}=0,6.5,13$ and 14$)$. For further understanding the HER mechanism of FeCoP, the authors built FeCoP model and calculated the adsorption behavior of $\mathrm{H}_{2} \mathrm{O}(-0.05 \mathrm{eV})$. The results indicate a more thermodynamically favorable $\mathrm{H}_{2} \mathrm{O}$ adsorption on FeCoP, which results in the low reaction barrier of FeCoP in basic electrolyte. In another work, similar results have been discussed. The $\mathrm{NiCOSe}_{2}$ nanosheets on nickel foam were obtained from NiCoLDH nanosheets through selenization [154]. The authors calculated the adsorption energies of $\mathrm{H}_{2} \mathrm{O}$ and $\mathrm{H}^{+}$to explain the outstanding HER performance under all $\mathrm{pH}$ electrolytes. The calculated results show that the $\mathrm{NiCOSe}_{2}$ had the larger adsorption value compared with $\mathrm{NiSe}_{2}$, which indicates that the doped Co would decrease the energy barriers for adsorbing $\mathrm{H}_{2} \mathrm{O}$ and $\mathrm{H}^{+}$of $\mathrm{NiSe}_{2}$. Our group reported an efficient HER electrocatalysts of $\left(\mathrm{Fe}_{x} \mathrm{Ni}_{1-x}\right)_{2} \mathrm{P}$ at all $\mathrm{pH}$ values [69]. After adjusting the appropriate amount of Fe doping into $\mathrm{Ni}_{2} \mathrm{P}$, we obtained the $\left(\mathrm{Fe}_{0.048} \mathrm{Ni}_{0.952}\right)_{2} \mathrm{P}$ with excellent HER performance and outstanding stability at high current density $\left(100 \mathrm{~mA} \mathrm{~cm}^{-2}\right)$ at all $\mathrm{pH}$ values. According the amount of doped $\mathrm{Fe}$, we designed different models of $\mathrm{Fe}_{x} \mathrm{Ni}_{84-x} \mathrm{P}_{42}$ to represent $\left(\mathrm{Fe}_{x} \mathrm{Ni}_{1-x}\right)_{2} \mathrm{P}$ catalysts and calculated the hydrogen adsorption free energy $\left(\Delta G_{\mathrm{H}^{*}}\right)$ and water dissociation energy $\left(\Delta G_{\mathrm{H} 20}\right)$. The calculated results show that the doped Fe could significantly decrease the absolute value of $\Delta G_{\mathrm{H}^{*}}$ and $\Delta G_{\mathrm{H} 2 \mathrm{O}}$, which indicates that the doped Fe could reduce the reaction barrier of HER under all $\mathrm{pH}$ electrolytes. Besides, according to the charge density difference calculations, we found that the doped Fe could make the active sites more active. The above reports are of great significance for the development and application towards neutral HER catalysts at high current density.

\section{Perspectives and future directions}

This review highlights the recent research in the development of NiFe-based materials on nickel foam for OER and HER. Nickel foam not only can serve as an ideal catalyst substrate due to its good conductivity and porosity, but also can participate in the reaction as the reactant. Meanwhile, nickel foam can keep the stability under $0.5 \mathrm{M} \mathrm{H}_{2} \mathrm{SO}_{4}$ for a long time during the appropriate voltage range, which relatively expands its application range.
As outlined in our review, numerous works reported that the combination of NiFe-based materials and nickel foam has considerable advances on OER and HER performance and stability. However, there are still several challenges in NiFe-based catalysts on nickel foam: (i) the role of Fe is sketchy in most researches, especially the specific doped amount; (ii) the reaction mechanism is still in its infancy and the theoretical research is deficient; (iii) the real active site is controversial in both OER and HER. To solve these issues, some advanced methods should be applied to future studies of NiFe-based catalysts on nickel foam, such as in situ spectroscopy and theoretical calculations. The understanding of basic mechanism is beneficial to discover the advanced NiFe-based catalysts with higher activity and stability.

\section{Acknowledgments}

This work is financially supported by the National Natural Science Foundation of China (Nos. 51473081 and 51672143), Taishan Scholars Program, Outstanding Youth of Natural Science in Shandong Province (JQ201713), Natural Science Foundation of Shandong Province (ZR2017MEM018) and ARC Discovery Project (No. 170103317).

\section{References}

[1] J.S. Luo, J.H. Im, M.T. Mayer, M. Schreier, M.K. Nazeeruddin, N.G. Park, S.D. Tilley, H.J. Fan, M. Gratzel, Science 345 (2014) 1593-1596.

[2] C.C.L. McCrory, S. Jung, I.M. Ferrer, S.M. Chatman, J.C. Peters, T.F. Jaramillo, J. Am. Chem. Soc. 137 (2015) 4347-4357.

[3] M. Gong, W. Zhou, M.C. Tsai, J.G. Zhou, M.Y. Guan, M.C. Lin, B. Zhang, Y.F. Hu, D.Y. Wang, J. Yang, S.J. Pennycook, B.J. Hwang, H.J. Dai, Nat. Commun. 5 (2014) 4695.

[4] J.H. Wang, W. Cui, Q. Liu, Z.C. Xing, A.M. Asiri, X.P. Sun, Adv. Mater. 28 (2016) 215-230.

[5] Y. Gu, S. Chen, J. Ren, Y.A. Jia, C.M. Chen, S. Komarneni, D.J. Yang, X.D. Yao, ACS Nano 12 (2018) 245-253.

[6] L.L. Feng, G.T. Yu, Y.Y. Wu, G.D. Li, H. Li, Y.H. Sun, T. Asefa, W. Chen, X.X. Zou, J. Am. Chem. Soc. 137 (2015) 14023-14026.

[7] C. Tang, N.Y. Cheng, Z.H. Pu, W. Xing, X.P. Sun, Angew. Chem. Int. Ed. 54 (2015) 9351-9355.

[8] Q. Liu, S. Gu, C.M. Li, J. Power Sources 299 (2015) 342-346.

[9] K. Mamtani, D. Jain, D. Dogu, V. Gustin, S. Gunduz, A.C. Co, U.S. Ozkan, Appl. Catal. B 220 (2018) 88-97.

[10] K.W. Wang, X.L. She, S. Chen, H.L. Liu, D.H. Li, Y. Wang, H.W. Zhang, D.J. Yang X.D. Yao, J. Mater. Chem. A 6 (2018) 5560-5565.

[11] J. Wang, F. Xu, H.Y. Jin, Y.Q. Chen, Y. Wang, Adv. Mater. 29 (2017) 1605838.

[12] Y.X. Zhao, C. Chang, F. Teng, Y.F. Zhao, G.B. Chen, R. Shi, G.I.N. Waterhouse, W.F. Huang, T.R. Zhang, Adv. Energy Mater. 7 (2017) 1700005.

[13] M.M. Najafpour, S. Madadkhani, M. Tavahodi, Int. J. Hydrogen Energy 42 (2017) 60-67.

[14] T. Yoshinaga, M. Saruyama, A. Xiong, Y. Ham, Y.B. Kuang, R. Niishiro, S. Akiyama, M. Sakamoto, T. Hisatomi, K. Domen, T. Teranishi, Nanoscale 10 (2018) 10420.

[15] H.N. Ren, Z.H. Huang, Z.Y. Yang, S.J. Tang, F.Y. Kang, R.T. Lv, J. Energy Chem. 26 (2017) $1217-1222$.

[16] J.T. Ren, Z.P. Hu, C. Chen, Y.P. Liu, Z.Y. Yuan, J. Energy Chem. 26 (2017) 11961202.

[17] Y.Y. Wu, Y.P. Liu, G.D. Li, X. Zou, X.R. Lian, D.J. Wang, L. Sun, T. Asefa, X.X. Zou, Nano Energy 35 (2017) 161-170.

[18] L. Zhang, B.R. Liu, N. Zhang, M.M. Ma, Nano Res. 11 (2018) 323-333.

[19] M.D. Zhang, Q.B. Dai, H.G. Zheng, M.D. Chen, L.M. Dai, Adv. Mater. 30 (2018) 1705431.

[20] Z.Q. Zhou, N. Mahmood, Y.C. Zhang, L. Pan, L. Wang, X.W. Zhang, J.J. Zou, J. Energy Chem. 26 (2017) 1223-1230.

[21] H. Li, P. Wen, O Li, C.C. Dun, J.H. Xing, C. Lu, S. Adhikari, L. Jiang, D.L. Carroll, S.M. Geyer, Adv. Energy Mater. 7 (2017) 1700513.

[22] X.J. She, J.J. Wu, H. Xu, J. Zhong, Y. Wang, Y.H. Song, K.Q. Nie, Y. Liu, Y.C. Yang M.T.F. Rodrigues, R. Vajtai, J. Lou, D.L. Du, H.M. Li, P.M. Ajayan, Adv. Energy Mater. 7 (2017) 1700025.

[23] J. Deng, H.J. Zhang, Y. Zhang, P. Luo, L. Liu, Y. Wang, J. Power Sources 372 (2017) 46-53.

[24] L. Fang, Z.Q. Jiang, H.T. Xu, L. Liu, Y.X. Guan, X. Gu, Y. Wang, J. Catal. 357 (2018) 238-246.

[25] Y. Gao, F.X. Wu, H. Chen, J. Energy Chem. 26 (2017) 428-432.

[26] M. Li, T.T. Liu, X.J. Bo, M. Zhou, L.P. Guo, J. Mater. Chem. A 5 (2017) 5413-5425.

[27] P.T. Liu, D.Q. Gao, W. Xiao, L. Ma, K. Sun, P.X. Xi, D.S. Xue, J. Wang, Adv. Funct. Mater. 28 (2018) 1706928.

[28] T.T.H. Nguyen, J. Lee, J. Bae, B. Lim, Chem. Eur J. 24 (2018) 4724-4728.

[29] C. Tang, H.F. Wang, Q. Zhang, Accounts Chem. Res. 51 (2018) 881-889. 
[30] C. Tang, H.S. Wang, H.F. Wang, Q. Zhang, G.L. Tian, J.Q. Nie, F. Wei, Adv. Mater. 27 (2015) 4516-4522.

31] N.K. Chaudhari, H. Jin, B. Kim, K. Lee, Nanoscale 9 (2017) 12231-12247.

[32] J.L. He, B.B. Hu, Y. Zhao, Adv. Funct. Mater. 26 (2016) 5998-6004

[33] N.K. Chaudhari, S. Chaudhari, J.S. Yu, Chemsuschem 7 (2014) 3102-3111.

[34] N.K. Chaudhari, M.S. Kim, T.S. Bae, J.S. Yu, Electrochim. Acta 114 (2013) 60-67.

[35] X.J. Chen, G.F. Zeng, T.T. Gao, Z.Y. Jin, Y.J. Zhang, H.Y. Yuan, D. Xiao, Electrochem. Commun. 74 (2017) 42-47.

[36] Y.J. Chen, Z.Y. Ren, H.Y. Fu, X. Zhang, G.H. Tian, H.G. Fu, Small 14 (2018) 1800763.

[37] S.C. Du, Z.Y. Ren, J. Zhang, J. Wu, W. Xi, J.Q. Zhu, H.G. Fu, Chem. Commun. 51 (2015) 8066-8069.

[38] C. Hang, J. Zhang, J.W. Zhu, W.Q. Li, Z.K. Kou, Y.H. Huang, Adv. Energy. Mater. 8 (2018) 1703539.

[39] L. Sun, T. Wang, L. Zhang, Y.J. Sun, K.W. Xu, Z.F. Dai, F. Ma, J. Power Sources 377 (2018) 142-150.

[40] J. Wang, H.X. Zhong, Z.L. Wang, F.L. Meng, X.B. Zhang, ACS Nano 10 (2016) 2342-2348

[41] T.Y. Ma, S. Dai, S.Z. Qiao, Mater. Today 19 (2016) 265-273.

[42] M.Y. Gao, C. Yang, Q.B. Zhang, J.R. Zeng, X.T. Li, Y.X. Hua, C.Y. Xu, P. Dong, J. Mater. Chem. A 5 (2017) 5797-5805.

[43] X. Gao, J. Li, R. Du, J.Y. Zhou, M.Y. Huang, R. Liu, J. Li, Z.Q. Xie, L.Z. Wu, Z.F. Liu, J. Zhang, Adv. Mater. 29 (2017) 1605308.

[44] N. Jiang, B. You, M.L. Sheng, Y.J. Sun, Angew. Chem. Int. Ed. 54 (2015) 62516254.

[45] N. Jiang, B. You, M.L. Sheng, Y.J. Sun, Chemcatchem 8 (2016) 106-112.

[46] M. Blasco-Ahicart, J. Soriano-Lopez, J.R. Galan-Mascaros, Chemelectrochem 4 (2017) 3296-3301.

[47] T. Butburee, Y. Bai, H.J. Wang, H.J. Chen, Z.L. Wang, G. Liu, J. Zou, P. Khemthong, G.Q.M. Lu, L.Z. Wang, Adv. Mater. 30 (2018) 1705666.

[48] G.M. Wang, H.Y. Wang, Y.C. Ling, Y.C. Tang, X.Y. Yang, R.C. Fitzmorris, C.C. Wang, J.Z. Zhang, Y. Li, Nano Lett. 11 (2011) 3026-3033.

[49] Z.W. Wang, X.L. Li, H. Ling, C.K. Tan, L.P. Yeo, A.C. Grimsdale, A.I.Y. Tok, Small 14 (2018) 1800395.

[50] A. Landman, H. Dotan, G.E. Shter, M. Wullenkord, A. Houaijia, A. Maljusch, G.S. Grader, A. Rothschild, Nat. Mater. 16 (2017) 646-651.

[51] H.Y. Li, S.M. Chen, X.F. Jia, B. Xu, H.F. Lin, H.Z. Yang, L. Song, X. Wang, Nat. Commun. 8 (2017) 15377.

[52] L. Zhou, M.F. Shao, M. Wei, X. Duan, J. Energy Chem. 26 (2017) 1094-1106.

[53] L. Zhou, M.F. Shao, C. Zhang, J.W. Zhao, S. He, D.M. Rao, M. Wei, D.G. Evans, X. Duan, Adv. Mater. 29 (2017) 1604080.

[54] Y.P. Liu, X. Liang, L. Gu, Y. Zhang, G.D. Li, X.X. Zou, J.S. Chen, Nat. Commun. 9 (2018) 2609

[55] X. Liu, B. You, Y.J. Sun, ACS Sustain. Chem. Eng. 5 (2017) 4778-4784.

[56] C.C. Du, M.X. Shang, J.X. Mao, W.B. Song, J. Mater. Chem. A 5 (2017) 1594015949.

[57] J.Z. Li, G.D. Wei, Y.K. Zhu, Y.L. Xi, X.X. Pan, Y. Ji, I.V. Zatovsky, W. Han, J. Mater Chem. A 5 (2017) 14828-14837.

[58] L. Yang, Z.L. Guo, J. Huang, Y.N. Xi, R.J. Gao, G. Su, W. Wang, L.X. Cao, B.H. Dong, Adv. Mater. 29 (2017) 1704574.

[59] C.Z. Yuan, L. Yang, L.R. Hou, L.F. Shen, X.G. Zhang, X.W. Lou, Energy Environ. Sci. 5 (2012) 7883-7887.

[60] A. Sivanantham, P. Ganesan, S. Shanmugam, Adv. Funct. Mater. 26 (2016) 4661-4672.

[61] C. Tang, H.F. Wang, X.L. Zhu, B.Q. Li, Q. Zhang, Part. Part. Syst. Char 33 (2016) 473-486.

[62] J.S. Wang, J. Liu, B. Zhang, H.Z. Wan, Z.S. Li, X. Ji, K. Xu, C. Chen, D. Zha, L. Miao, J.J. Jiang, Nano Energy 42 (2017) 98-105

[63] D. Voiry, M. Chhowalla, Y. Gogotsi, N.A. Kotov, Y. Li, R.M. Penner, R.E. Schaak, P.S. Weiss, ACS Nano 12 (2018) 9635-9638.

[64] J.L. Liu, Y. Zheng, Z.Y. Wang, Z.G. Lu, A. Vasileff, S.Z. Qiao, Chem. Commun. 54 (2018) 463-466.

[65] K.M. Xiao, L. Zhou, M.F. Shao, M. Wei, J. Mater. Chem. A 6 (2018) 7585-7591.

[66] S. Jiang, Y. Liu, W. Xie, M. Shao, J. Energy Chem. 000 (2018) 1-5.

[67] B. Wang, C. Tang, H.F. Wang, X. Chen, R. Cao, Q. Zhang, Adv. Mater. (2018) e1805658.

[68] H. Li, X.L. Zhao, H.L. Liu, S. Chen, X.F. Yang, C.X. Lv, H.W. Zhang, X.L. She, D.J. Yang, Small 14 (2018) 1802824.

[69] W. Zhang, Y. Zou, H. Liu, S. Chen, X. Wang, H. Zhang, X. She, D. Yang, Nano Energy 56 (2019) 813-822.

[70] J. Bao, X.D. Zhang, B. Fan, J.J. Zhang, M. Zhou, W.L. Yang, X. Hu, H. Wang, B.C. Pan, Y. Xie, Angew. Chem. Int. Ed. 54 (2015) 7399-7404.

[71] J.T. Zhang, Z.H. Zhao, Z.H. Xia, L.M. Dai, Nat. Nanotechnol. 10 (2015) 444-452.

[72] N. Danilovic, R. Subbaraman, K.C. Chang, S.H. Chang, Y.J. Kang, J. Snyder, A.P. Paulikas, D. Strmcnik, Y.T. Kim, D. Myers, V.R. Stamenkovic, N.M. Markovic, Angew. Chem. Int. Ed. 53 (2014) 14016-14021.

[73] R. Forgie, G. Bugosh, K.C. Neyerlin, Z.C. Liu, P. Strasser, Electrochem. Solid St 13 (2010) D36-D39.

[74] F.J. Li, Y. Chen, D.M. Tang, Z.L. Jian, C. Liu, D. Golberg, A. Yamada, H.S. Zhou, Energy Environ. Sci. 7 (2014) 1648-1652.

[75] T. Reier, M. Oezaslan, P. Strasser, ACS Catal. 2 (2012) 1765-1772

[76] S. Chen, J.J. Duan, W. Han, S.Z. Qiao, Chem. Commun. 50 (2014) 207-209.

[77] S. Chen, G.X. Liu, H. Yadegari, H.H. Wang, S.Z. Qiao, J. Mater. Chem. A 3 (2015) 2559-2563.

[78] C. Tang, H.F. Wang, H.S. Wang, F. Wei, Q. Zhang, J. Mater. Chem. A 4 (2016) 3210-3216.
[79] F. Yan, C. Zhu, S. Wang, Y. Zhao, X. Zhang, C. Li, Y. Chen, J. Mater. Chem. A 4 (2016) 6048-6055.

[80] X.T. Yuan, H.X. Ge, X. Wang, C.L. Dong, W.J. Dong, M.S. Riaz, Z.W. Xu, J.X. Zhang, F.Q. Huang, ACS Energy Lett. 2 (2017) 1208-1213.

[81] Y.F. Zhao, B. Sun, X.D. Huang, H. Liu, D.W. Su, K.N. Sun, G.X. Wang, J. Mater Chem. A 3 (2015) 5402-5408.

[82] M. Bernicke, B. Eckhardt, A. Lippitz, E. Ortel, D. Bernsmeier, R. Schmack, R. Kraehnert, Chemistryselect 1 (2016) 482-489.

[83] J. Wang, K. Li, H.X. Zhong, D. Xu, Z.L. Wang, Z. Jiang, Z.J. Wu, X.B. Zhang, Angew. Chem. Int. Ed. 54 (2015) 10530-10534.

[84] R. Xu, R. Wu, Y.M. Shi, J.F. Zhang, B. Zhang, Nano Energy 24 (2016) 103-110.

[85] W.X. Zhu, X.Y. Yue, W.T. Zhang, S.X. Yu, Y.H. Zhang, J. Wang, J.L. Wang, Chem Commun. 52 (2016) 1486-1489.

[86] B.M. Hunter, W. Hieringer, J.R. Winkler, H.B. Gray, A.M. Muller, Energy Environ. Sci. 9 (2016) 1734-1743.

[87] X.G. Liu, X. Wang, X.T. Yuan, W.J. Dong, F.Q. Huang, J. Mater. Chem. A 4 (2016) $167-172$.

[88] Z. Lu, W.W. Xu, W. Zhu, Q. Yang, X.D. Lei, J.F. Liu, Y.P. Li, X.M. Sun, X. Duan, Chem Commun. 50 (2014) 6479-6482.

[89] R. Chen, G.Z. Sun, C.J. Yang, L.P. Zhang, J.W. Miao, H.B. Tao, H.B. Yang, J.Z. Chen, P. Chen, B. Liu, Nanoscale Horiz. 1 (2016) 156-160.

[90] K. Fan, H. Chen, Y.F. Ji, H. Huang, P.M. Claesson, Q. Daniel, B. Philippe H. Rensmo, F.S. Li, Y. Luo, L.C. Sun, Nat. Commun. 7 (2016) 11981.

[91] S.M. Yin, WG. Tu, Y. Sheng, Y.H. Du, K. Markus, B. Armando, R. Xu, Adv. Mater 30 (2018) 1705106

[92] M. Gorlin, P. Chernev, J.F. de Araujo, T. Reier, S. Dresp, B. Paul, R. Krahnert, H. Dau, P. Strasser, J Am Chem Soc. 138 (2016) 5603-5614.

[93] Z.H. Li, M.F. Shao, H.L. An, Z.X. Wang, S.M. Xu, M. Wei, D.G. Evans, X. Duan, Chem. Sci. 6 (2015) 6624-6631.

[94] X. Long, S. Xiao, Z.L. Wang, X.L. Zheng, S.H. Yang, Chem. Commun. 51 (2015) $1120-1123$.

[95] H.X. Liu, Y.R. Wang, X.Y. Lu, Y. Hu, G.Y. Zhu, R.P. Chen, L.B. Ma, H.F. Zhu, Z.X. Tie, J. Liu, Z. Jin, Nano Energy 35 (2017) 350-357.

[96] Z.Y. Lu, L. Qian, Y. Tian, Y.P. Li, X.M. Sun, X. Duan, Chem. Commun. 52 (2016) 908-911.

[97] G.B. Chen, T. Wang, J. Zhang, P. Liu, H.J. Sun, X.D. Zhuang, M.W. Chen, X.L. Feng, Adv. Mater. 30 (2018) 1706279.

[98] P.S. Li, X.X. Duan, Y. Kuang, Y.P. Li, G.X. Zhang, W. Liu, X.M. Sun, Adv. Energy Mater. 8 (2018) 1703341

[99] X. Zou, Y.P. Liu, G.D. Li, Y.Y. Wu, D.P. Liu, W. Li, H.W. Li, D.J. Wang, Y. Zhang X.X. Zou, Adv. Mater. 29 (2017) 1700404.

[100] Y. Yang, L.N. Dang, M.J. Shearer, H.Y. Sheng, W.J. Li, J. Chen, P. Xiao, Y.H. Zhang R.J. Hamers, S. Jin, Adv. Energy Mater. 8 (2018) 1703189.

[101] D.J. Zhou, Z. Cai, Y.M. Bi, W.L. Tian, M. Luo, Q. Zhang, Q. Zhang, Q.X. Xie J.D. Wang, Y.P. Li, Y. Kuang, X. Duan, M. Bajdich, S. Siahrostami, X.M. Sun, Nano Res. 11 (2018) 1358-1368.

[102] N. Han, F.P. Zhao, Y.G. Li, J. Mater. Chem. A 3 (2015) 16348-16353.

[103] S. Nayak, L. Mohapatra, K. Parida, J. Mater. Chem. A 3 (2015) 18622-18635.

[104] F. Song, X.L. Hu, Nat. Commun. 5 (2014) 4477.

[105] S.H. Zou, M.S. Burke, M.G. Kast, J. Fan, N. Danilovic, S.W. Boettcher, Chem. Mater. 27 (2015) 8011-8020.

106] D. Friebel, M.W. Louie, M. Bajdich, K.E. Sanwald, Y. Cai, A.M. Wise, M.J. Cheng D. Sokaras, T.C. Weng, R. Alonso-Mori, R.C. Davis, J.R. Bargar, J.K. Norskov, A. Nilsson, A.T. Bell, J. Am. Chem. Soc. 137 (2015) 1305-1313.

[107] X.D. Jia, Y.F. Zhao, G.B. Chen, L. Shang, R. Shi, X.F. Kang, G.I.N. Waterhouse L.Z. Wu, C.H. Tung, T.R. Zhang, Adv. Energy Mater. 6 (2016) 1502585

[108] K. Xu, P.Z. Chen, X.L. Li, Y. Tong, H. Ding, X.J. Wu, W.S. Chu, Z.M. Peng, C.Z. Wu, Y. Xie, J. Am. Chem. Soc. 137 (2015) 4119-4125.

[109] B. Zhang, C.H. Xiao, S.M. Xie, J. Liang, X. Chen, Y.H. Tang, Chem. Mater. 28 (2016) 6934-6941.

[110] P.Z. Chen, K. Xu, Z.W. Fang, Y. Tong, J.C. Wu, X.L. Lu, X. Peng, H. Ding, C.Z. Wu Y. Xie, Angew. Chem. Int. Ed. 54 (2015) 14710-14714.

[111] Y.Y. Wang, C. Xie, Z.Y. Zhang, D.D. Liu, R. Chen, S.Y. Wang, Adv. Funct. Mater 28 (2018) 1870119.

112] P.Z. Chen, T.P. Zhou, M.X. Zhang, Y. Tong, C.G. Zhong, N. Zhang, L.D. Zhang C.Z. Wu, Y. Xie, Adv. Mater. 29 (2017) 1701584

[113] Y.S. Jin, X. Yue, H.Y. Du, K. Wang, S.L. Huang, P.K. Shen, J. Mater. Chem. A 6 (2018) 5592-5597.

[114] M. Jiang, Y.J. Li, Z.Y. Lu, X.M. Sun, X. Duan, Inorg. Chem. Front 3 (2016) 630 634.

[115] Y. Wang, B. Kong, D.Y. Zhao, H.T. Wang, C. Selomulya, Nano Today 15 (2017) 26-55.

[116] J. Masud, S. Umapathi, N. Ashokaan, M. Nath, J. Mater. Chem. A 4 (2016) 9750-9754.

[117] Y. Yan, B. Zhao, S.C. Yi, X. Wang, J. Mater. Chem. A 4 (2016) 13005-13010.

[118] Z. Zhang, B.P. Lu, J.H. Hao, W.S. Yang, J.L. Tang, Chem. Commun. 50 (2014) 11554-11557.

[119] H.W. Man, C.S. Tsang, M.M. Li, J. Mo, B. Huang, L.Y.S. Lee, Y.C. Leung K.Y. Wong, S.C.E. Tsang, Chem. Commun. (Camb.) 54 (2018) 8630-8633.

[120] Y.J. Li, H.C. Zhang, M. Jiang, Q. Zhang, P.L. He, X.M. Sun, Adv. Funct. Mater. 27 (2017) 1702513

[121] P.Y. Wang, Z.H. Pu, Y.H. Li, L. Wu, Z.K. Tu, M. Jiang, Z.K. Kou, I.S. Arniinu, S.C. Mu, ACS Appl. Mater. Inter. 9 (2017) 26001-26007.

[122] H. Liang, A.N. Gandi, C. Xia, M.N. Hedhili, D.H. Anjum, U. Schwingenschlogl H.N. Alshareef, ACS Energy Lett. 2 (2017) 1035-1042.

[123] J.H. Yu, G.Z. Cheng, W. Luo, J. Mater. Chem. A 5 (2017) 11229-11235.

849 850 
[124] L.S. Peng, S.S.A. Shah, Z.D. Wei, Chinese J. Catal. 39 (2018) 1575-1593.

[125] N.Y. Cheng, Q. Liu, A.M. Asiri, W. Xing, X.P. Sun, J. Mater. Chem. A 3 (2015) 23207-23212.

[126] J.H. Yu, G.Z. Cheng, W. Luo, J. Mater. Chem. A 5 (2017) 15838-15844.

[127] P. Ganesan, A. Sivanantham, S. Shanmugam, J. Mater. Chem. A 4 (2016) 16394-16402.

128] X.W. Zhou, Y.L. Gan, J.J. Du, D.N. Tian, R.H. Zhang, C.Y. Yang, Z.X. Dai, J. Power Sources 232 (2013) 310-322.

129] M.G. Walter, E.L. Warren, J.R. McKone, S.W. Boettcher, Q.X. Mi, E.A. Santori, N.S. Lewis, Chem. Rev. 110 (2010) 6446-6473.

130] X. Long, G.X. Li, Z.L. Wang, H.Y. Zhu, T. Zhang, S. Xiao, W.Y. Guo, S.H. Yang, J. Am. Chem. Soc. 137 (2015) 11900-11903.

[131] R. Subbaraman, D. Tripkovic, D. Strmcnik, K.C. Chang, M. Uchimura, A.P. Paulikas, V. Stamenkovic, N.M. Markovic, Science 334 (2011) 1256-1260.

[132] R. Subbaraman, D. Tripkovic, K.C. Chang, D. Strmcnik, A.P. Paulikas, P. Hirunsit, M. Chan, J. Greeley, V. Stamenkovic, N.M. Markovic, Nat. Mater. 11 (2012) 550-557.

133] P. Zhang, J.J. Zhang, J.L. Gong, Chem. Soc. Rev. 43 (2014) 4395-4422.

$134]$ X.X. Zou, X.X. Huang, A. Goswami, R. Silva, B.R. Sathe, E. Mikmekova, T. Asefa, Angew. Chem. Int. Ed. 53 (2014) 4372-4376.

135] J. Lu, T.L. Xiong, W.J. Zhou, L.J. Yang, Z.H. Tang, S.W. Chen, ACS Appl. Mater. Inter. 8 (2016) 5065-5069.

136] T.T. Liu, X. Ma, D.N. Liu, S. Hao, G. Du, Y.J. Ma, A.M. Asiri, X.P. Sun, L. Chen, ACS Catal. 7 (2017) 98-102.

[137] Y.Q. Sun, L.F. Hang, Q. Shen, T. Zhang, H.L. Li, X.M. Zhang, X.J. Lyu, Y. Li, Nanoscale 9 (2017) 16674-16679.

[138] Y.M. Shi, Y. Xu, S.F. Zhuo, J.F. Zhang, B. Zhang, ACS Appl. Mater. Inter 7 (2015) 2376-2384.
[139] Z.Z. Ma, R.X. Li, M. Wang, H.J. Meng, F. Zhang, X.Q. Bao, B. Tang, X.G. Wang, 963 Electrochim. Acta 219 (2016) 194-203.

[140] C. Ray, S.C. Lee, B.J. Jin, A. Kundu, J.H. Park, S.C. Jun, ACS Sustain. Chem. Eng. 965 6 (2018) 6146-6156.

[141] N.A. Assuncao, M.J. Giz, G. Tremiliosi-Filho, E.R. Gonzalez, J. Electrochem Soc. 967 144 (1997) 2794-2800.

[142] J.H. Xing H. Li, M.M.C. Cheng S.M. Geyer, KYS. Ng J. Mater. Chem. A 4 (2016) 969 13866-13873.

[143] C.H. Xiao, B. Zhang, D. Li, Electrochim. Acta 242 (2017) 260-267.

[144] J. Hu, Y. Ou, Y. . Li, D. Gao, Y. Z Zhang P. Xiao, ACS Sustain. Chem. Eng. 6972 (2018) 11724-11733.

[145] C. Tang, R. Zhang, W.B. Lu, L.B. He, X. Jiang, A.M. Asiri, X.P. Sun, Adv. Mater. 29 (2017) 1602441.

[146] ZJ. Chen, G.X. Cao, LY. Gan, H. Dai, N. Xu, M J Zang H B. Dai, H. Wu, P. Wang 976 ACS Catal. 8 (2018) 8866-8872.

[147] B. You, Y.J. Sun, Adv. Energy Mater. 6 (2016) 1502333.

[148] J.T. Ren, Z.Y. Yuan, ACS Sustain. Chem. Eng. 5 (2017) 7203-7210.

[149] N. Yang, C. Tang, K.Y. Wang, G. Du, A.M. Asiri, X.P. Sun, Nano Res. 9 (2016) 3346-3354.

[150] G. Zhang, Y.S. Feng, W.T. Lu, D. He, C.Y. Wang, Y.K. Li, X.Y. Wang, F.F. Cao, ACS Catal. 8 (2018) 5431-5441.

[151] B. Hinnemann, P.G. Moses, J. Bonde, K.P. Jorgensen, J.H. Nielsen, S. Horch, I. Chorkendorff, J.K. Norskov, J. Am. Chem. Soc. 127 (2005) 5308-5309.

[152] X. Shang J.F. Qin, J.H. Lin, B. Dong, J.Q. Chi, Z.Z. Liu, L. Wang, Y.M. Chai, 986 C.G. Liu, J. Colloid Interf Sci. 523 (2018) 121-132.

[153] L. Zhou, M.G. Shao, J.B. Li, S. Jiang, M. Wei, X. Duan, Nano Energy 41 (2017) 583-590.

[154] B. Liu, Y. Z Zhao, H.Q Peng ZY Zhang C.K. Sit, MF Yuen, TR. Zhang C. S. Lee, 990 W.J. Zhang, Adv. Mater. 29 (2017) 1606521. 